\title{
Effects of Geometrical Parameters in Gravitational Water Vortex Turbines with Conical Basin
}

\author{
Tri Ratna Bajracharya, ${ }^{1,2}$ Shree Raj Shakya ${ }^{1},{ }^{1,2}$ Ashesh Babu Timilsina ${ }^{(1 D,}{ }^{1,2}$ \\ Jhalak Dhakal $\mathbb{D},{ }^{1}$ Subash Neupane, ${ }^{1}$ Ankit Gautam $\mathbb{D}^{1,2}$ and Anil Sapkota $\mathbb{D}^{1,2}$ \\ ${ }^{1}$ Department of Mechanical Engineering, Pulchowk Campus, Institute of Engineering, Tribhuvan University, Lalitpur, Nepal \\ ${ }^{2}$ Centre for Energy Studies, Institute of Engineering, Tribhuvan University, Lalitpur, Nepal \\ Correspondence should be addressed to Anil Sapkota; anil.apk13@gmail.com
}

Received 22 December 2019; Revised 18 August 2020; Accepted 20 October 2020; Published 2 December 2020

Academic Editor: Jing Shi

Copyright ( $\odot 2020$ Tri Ratna Bajracharya et al. This is an open access article distributed under the Creative Commons Attribution License, which permits unrestricted use, distribution, and reproduction in any medium, provided the original work is properly cited.

\begin{abstract}
Gravitational Water Vortex Power Plant (GWVPP) is an appropriate means to convert kinetic energy of water to rotational mechanical energy at the very low head site. This study aims to establish a basic reference for the design of the runner for the Gravitational Water Vortex Turbine (GWVT) with a conical basin. Seven different geometrical parameters have been identified for runner design, and the effect of these parameters on the system efficiency has been studied numerically and experimentally. The effect of these parameters has been studied over the range of speed with torque. The results from performance tests of these runners suggest that runner height is the most significant parameter to be considered in the design of a turbine runner for GWVPP with a conical basin. The results show that the efficiency of GWVT has improved up to $47.85 \%$ as obtained from experiments.
\end{abstract}

\section{Introduction}

The hydropower technology that generates power by utilizing head under $3 \mathrm{~m}$ is categorized as very low head hydropower which comprises largely untapped hydropower in form of streams, canal falls, and water supply dams $[1,2]$. Low head and small hydropower are almost benign in terms of carbon footprints [2], economical, and more suitable for fragile ecology and scattered populations [3,4]. Furthermore, the installation of the pico-hydro plant (up to $5 \mathrm{~kW}$ ) is cost-effective compared to several energy sources like solar $\mathrm{PV}$, grid extension, and diesel generator [5]. A multicriteria analysis by Williamson et al. [5] shows that Turgo and propeller turbines with a draft tube are the best solutions among turbines considered for low head, variable flow rate pico-hydro site in remote areas owing to ease of installation, operation, and maintenance. However, this study [5] encompasses only Pelton/Turgo wheels, water wheels, Archimedes Screw, propeller, radial, and cross-flow turbines. On the other hand, common low head hydropower turbines like Archimedes Screw, water wheels, and modified (miniaturized and simplified in design) conventional turbines have limited applications, due to poor part flow efficiency, manufacturing difficulties/cost, and uneconomical deployment [2].

Gravitational Water Vortex (GWV) is an ultra-low-head technology which uses the concept of free surface water vortex for power generation. Viktor Schauberger is the pioneer to conceptualize the use of vortex for power generation although his work did not make use of free surface water vortex [7] whereas the first use of free surface water vortex was done by Brown [8] with submerged outlet. Attempts have been made by Kouris [9] and Zotlöterer [10] in the development of technologies for power production from free surface water vortex but the successful deployment for power production was performed by Zotlöterer (Figure 1). The most notable change introduced was free stream discharge at the exit rather than the submerged exit implemented in previous practices. In the current practice, the minimal components in a GWV system are canal, basin, turbine, generator, and tailrace (Figure 1). The water stream is guided through an inlet canal into the round basin 


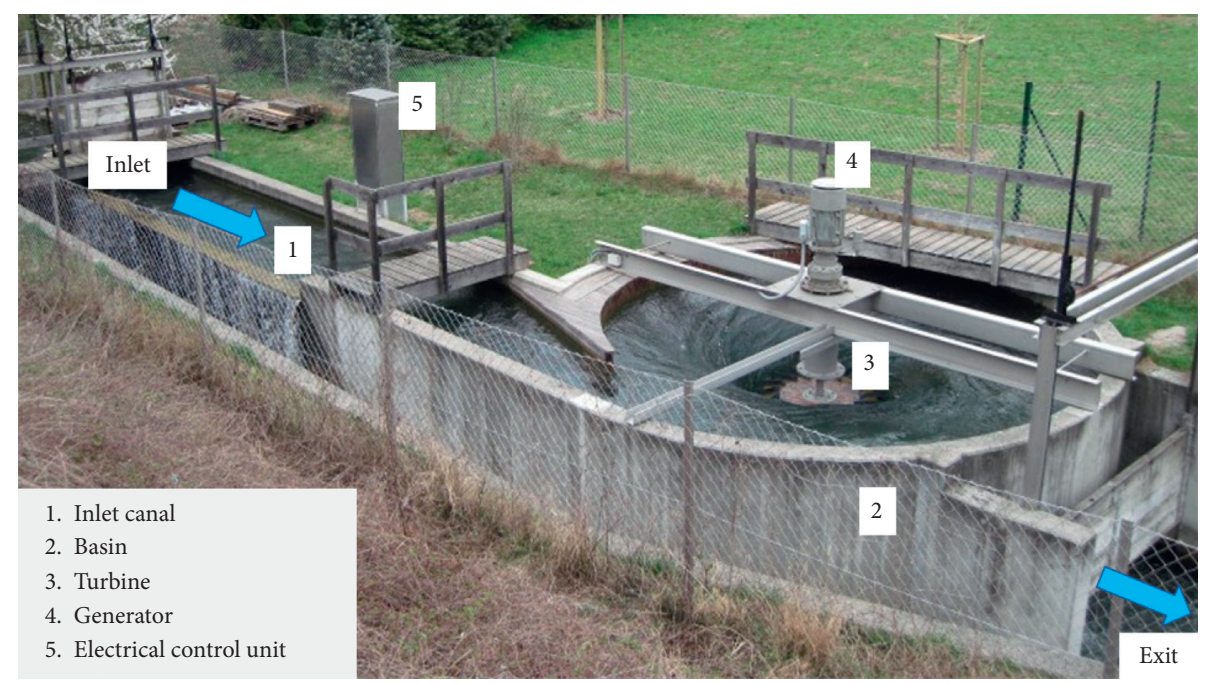

FIgURE 1: Basic components in a GWVPP_installation at Obergrafendorf, Austria (reproduced with permission from Zotlöterer).

tangentially inducing circulation. A combination of localized low pressure at the orifice (exit) and induced circulation at the inlet [11] forms a vortex pool. The inlet water stream strikes the runner blades, changes the flow direction at the blades surface, and finally exits the bottom hole into a free stream. The runner is placed concentrically above the exit hole and has two major parts, hub and blades. It is designed to be fully submerged into the vortex pool although the free surface depression at the center (also visible in Figure 1) exposes part of runner blades to the air. The hub is a hollow cylinder connected to the turbine shaft and blades are protrusions from the hub. There are claims that GWV also aerates the water in a gentle way unlike conventional hydropower-water cleaning effect-and has no effects on fish migration and lives due to the low speed of the turbine [12]; these claims, however, remain to be validated [6]. Although no specific operating range has been defined properly for GWV turbine, the operating range as proposed by Timilsina et al. [6] is shown in Figure 2 with a proposed head range of 0.7-2 $\mathrm{m}$ [12] which has a rather larger operating envelope than waterwheels and Archimedes Screw.

Studies on water vortices to date can be categorized into two facets: analytical study of flow patterns, supplemented by simulations and experiments, and lab pilot studies for power extraction purposes. Different configurations of basin and inlet conditions have been studied either analytically, computationally, experimentally, or any of the combinations [11, 13-21]. The important design parameters which determine the kinetic energy and configuration of water vortex include the height of water in the channel, the outlet orifice diameter, fluid flow conditions at the inlet, and the basin configuration [14]. Wanchat and Suntivarakorn [14] concluded that a cylindrical tank with an orifice at the bottom center with the incoming flow guided by a plate is the most suitable configuration to create the water vortex for the purpose of electricity generation. Wanchat et al. [15] investigated parameters, which affect the velocity vector field for GWVPP, which include the outlet orifice diameter, gravitational vortex head, and flow rate. Optimum vortex strength occurs within the range of orifice diameter to tank diameter ratio $(d / D)$ of $14-18 \%$, for low and high head sites, respectively, for the cylindrical basin, which thus maximizes the power output [11]. A comparative study of conical and cylindrical basins followed by experimental measurements showed that a more powerful vortex is formed in the conical basin $[17,19]$. Furthermore, the efficiency of the system was found to be more with a conical basin when tested with the same runner under a similar condition of head and flow. Brown [8] stated that the position of the runner in the vertical shaft needs to be adjusted for maximum efficiency conditions. Similarly, in a study of the conical basin by Marian et al. [22] on an analytical and numerical basis, the flow pattern was studied with and without placement of modified Francis runner/s cascaded in the basin. The study concluded that runner placed nearer to the outlet would harness power efficiently, and similar concluding remarks were given by Dhakal et al. as well [17]. An experimental study with a paddle-type runner for the cylindrical basin was done by Power et al. [21] by varying blade size, blade number, inlet flow rate, and inlet height. Runners were developed by the equal angular placement of 2 and 4 rectangular blades. The study concluded that turbine efficiency increases with blade area and blade number. For the runner tested, at the optimum position of runner placement, maximum efficiency of $15.1 \%$ is reported. On the contrary, Dhakal et al. had shown a decrease in efficiency when the number of blades increased from 6 to 12 [17]. The contradicting findings of Power et al. [21] and Dhakal et al. [17] require more investigation. Since the number of blades tested does not match in these studies, it suggests that maximum efficiency could be achieved for some blade number for either of the cases. Wichian and Suntivarakorn [23] studied the effect of the turbine baffle plate on the efficiency by using the CFD program along with the experimental verification. The tests done in different flow rates revealed that the turbine with 5 blades and $50 \%$ baffle plate increases the overall efficiency by $4.12 \%$, thus making it $38.68 \%$.

Different independent studies conducted to date are focused on the basin and its various geometrical parameters, but limited studies are carried out regarding GWV turbine, its 


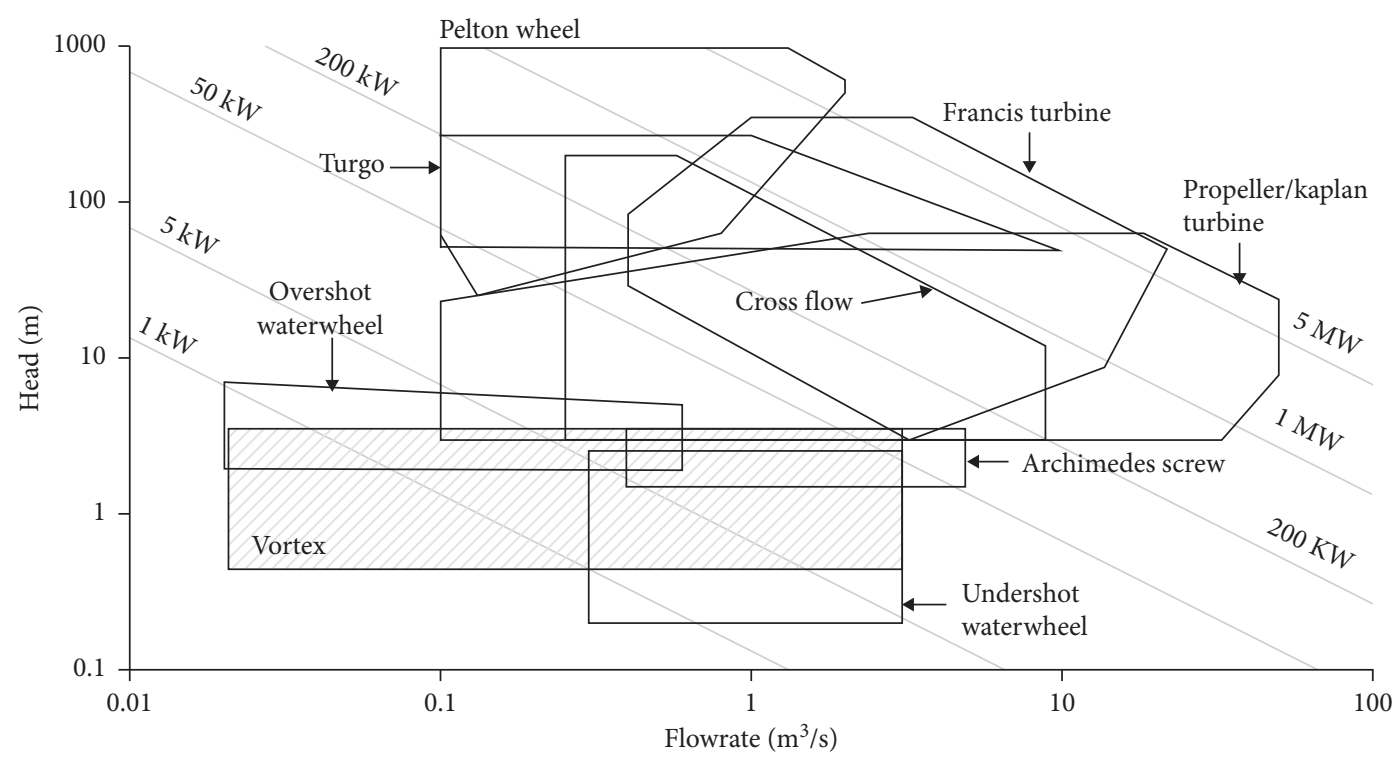

FIgURE 2: Operational area of GWVPP (adapted from [6]).

design, and parameters. Dhakal et al. [19] formulated the runner based on the principle of a cross-flow turbine. Moreover, the parameters used to date for runner design are somehow related only to the cylindrical basin with clearly unspecified design $[11,12,15,17,19]$. This study tries to describe the effect of these geometrical parameters on overall system efficiency. Starting with a simple paddle-type runner, the geometrical design parameters are introduced consecutively. The new design parameter is introduced to the optimal value obtained from the case. The rectangular section being the simplest form for the blade has been chosen at first while the consecutive parameters have been chosen considering design for manufacturability with locally available tools and workmanship.

\section{Study Design}

Turbines are devices that extract energy from a flowing fluid. In reaction turbines, the fluid stream hits the turbine blades followed by significant static pressure drop and change in fluid relative velocity across the turbine blades whereas in impulse turbines such effects are negligible. The geometry of the turbine is such that the fluid exerts torque on the rotor in the direction of its rotation [24, 25]. Thus, a proper runner design is pivotal for the maximum power production from the available flow condition. The different geometrical parameters introduced in the runner design are shown in Figure 3 whereas Figure 4 shows the order they have been introduced and studied. In total, twenty-two runners have been developed, and their performance was assessed experimentally and compared with that of numerical simulations. The twenty-two runners (six of the runners appear on more than one runner set; refer to Section 5) are divided into seven sets with four runners in each of the sets.

2.1. Geometrical Parameters. A general argument for the introduction of seven different parameters is presented here. The fluid motion in a vortical flow can be described with the

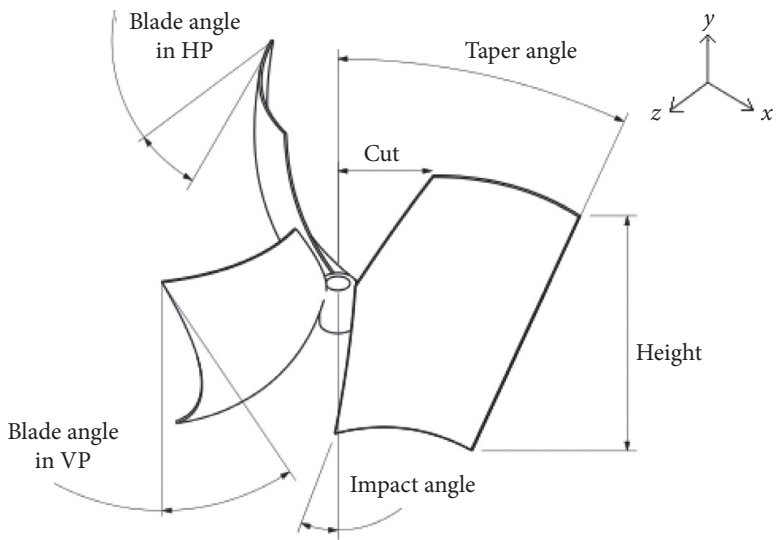

FIGURE 3: 3D view of parameters studied in runner design.

cylindrical coordinate system. So, the water stream in the conical basin has three velocity components (namely, $r, \theta$, and $z$ ). The parameters have been introduced progressively in this study. Studies $[17,21,26]$ have shown that a higher number of runner blades distort the vortex formation whereas a higher mass of the turbine is not beneficial in the efficient energy extraction process. Timilsina et al. [6] concluded that the power output and runner speed decrease beyond some critical turbine weight. Thus, an optimum weight range exists for which the efficiency is maximum. On the other hand, when the turbine components like a shaft, hub, etc. are kept unchanged, only the runner weight/dimensions can be varied. Hence, the runner weight can be related to the runner blade surface area. While the larger surface area provides more opportunity for the incoming jet to strike the runner blades, it also keeps pushing the water volume already present in the basin. The water volume on the backside of runner blades tries to oppose the rotating blades, similar to breaking jet effect in the Pelton wheel, which has been termed water drag here. Thus, the following geometrical 


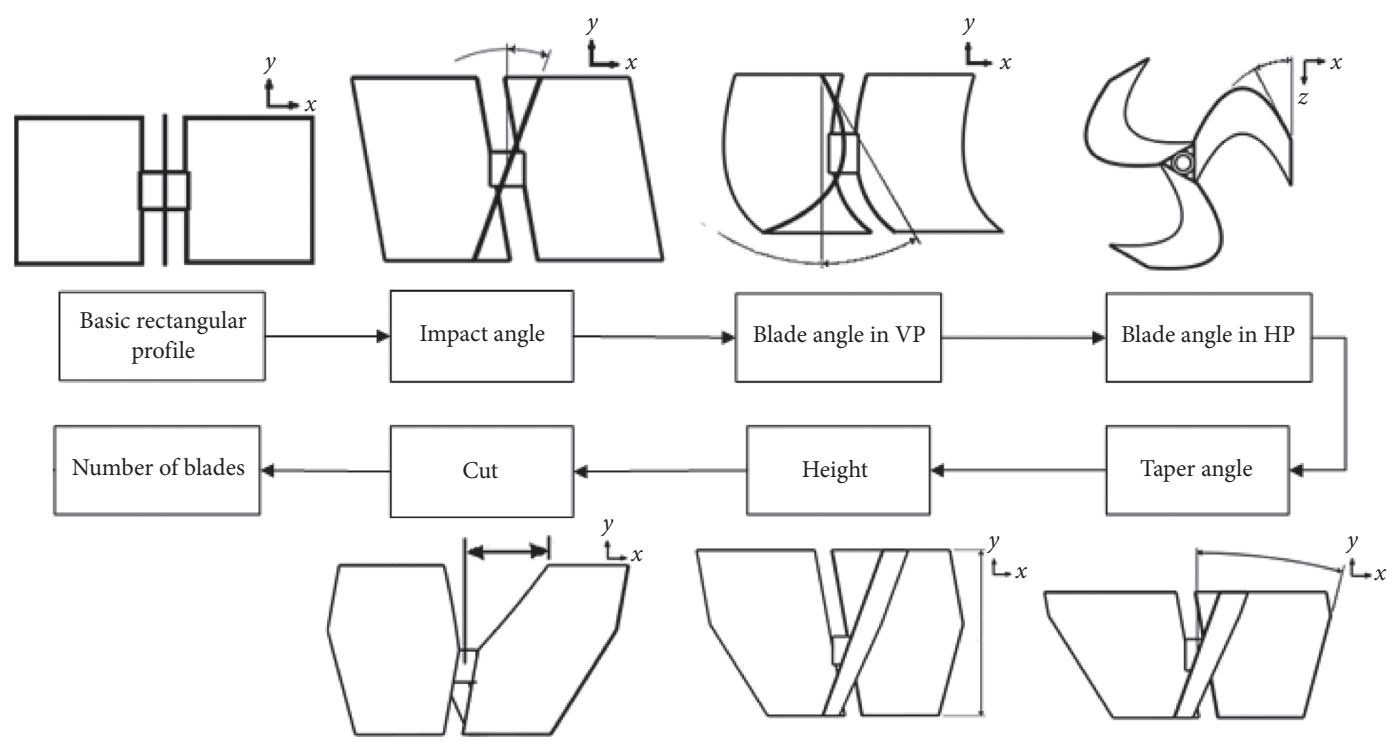

Figure 4: Flow of parameters studied.

parameters have been introduced trying to keep runner weight low with larger blade surface area and proper blade angles. The parameters have been illustrated in Figure 3.

\subsubsection{Impact Angle. Since the water flowing in the basin has} a $z$ component, a vertical flat plate is not an efficient choice for power extraction purposes. Thus, the runner blades require some inclination (impact angle), measured against VP [5]. So, the concept of the nozzle angle used in the Turgo turbine has been introduced here equivalently as an impact angle. The runner blade is tilted with respect to VP so that the incoming water stream hits the blade perpendicularly.

2.1.2. Blade Angle in VP and HP. In any turbine, the maximum energy transfer from the fluid to the turbine can be achieved with proper blade (inlet and outlet) angles and blade profile (curvature). Blade angle is the angle made by the fluid velocity with blade velocity at inlet/outlet. The axial momentum in the water stream can be extracted by the use of suitable blade angles in VP and radial and tangential momenta by blade angles in HP. Blade angles in VP have been studied first followed by blade angles in HP.

2.1.3. Taper Angle. For the parameters introduced above, the projection of an individual runner blade is rectangular. Thus, a gap exists between the outer edge of the runner blade and the basin wall; thus, water seeps out from that gap. The increase in energy output is achieved by tapering the outer edge of the runner blade. The length of the top edge has been changed keeping the bottom edge length constant. The taper angle is the angle made by the outer edge of the blade with the runner axis in VP.

2.1.4. Height. Since the runner inner and outer diameters are already limited by the hub and $\mathrm{OR}_{2}$, (Figure 5) the surface area can be varied by changing the runner height as well.
2.1.5. Cut. Researchers $[11,17,20]$ have shown that the free surface of water dips around the vortex center. Similarly, experiments have shown that the free surface maintains a curvature in presence of a turbine, and the turbine runner blades are not fully submerged in the rotating fluid, also predicted by Mulligan and Casserly [11]. A portion of the blade is removed only at the top inner edges (edge attached to the hub), thus removing a triangular part of the blade (Figure 5).

2.1.6. Number of Blades. Maximum power can be harnessed if the incoming water stream strikes the turbine blades continuously. This requires a higher number of blades, but increasing blade numbers can obstruct the water stream and change the flow regime. A higher blade number can increase drag which can overcome the power increase since lower efficiencies have been reported with higher blade numbers as well $[17,26]$. Thus, the number of blades is varied to determine the region for maximum runner efficiency.

While there are studies available discussing a few parameters and their efficacy, none of them have been able to present a suitable set of criteria to develop a runner for the available flow conditions. On the other hand, this study tries to incorporate basic turbine runner geometrical parameters for GWVPP and develop a turbine that can be manufactured even with lesser skill and less sophisticated tools. A paddle-type runner being the simplest form has been studied first followed by relevant geometries in a common impulse turbine, namely, impact angle and blade angle; impact angle was adapted from Turgo turbine. Although the turbine is being studied on the basis of an impulse turbine, the GWVT is actually inside the basin and thus basin geometry affects the turbine geometry. The enclosed turbine performance is accessed further by introducing parameters cut and taper angle. Two more parameters, height and blade number, are introduced to increase surface area, thus weight, of the runner to access 


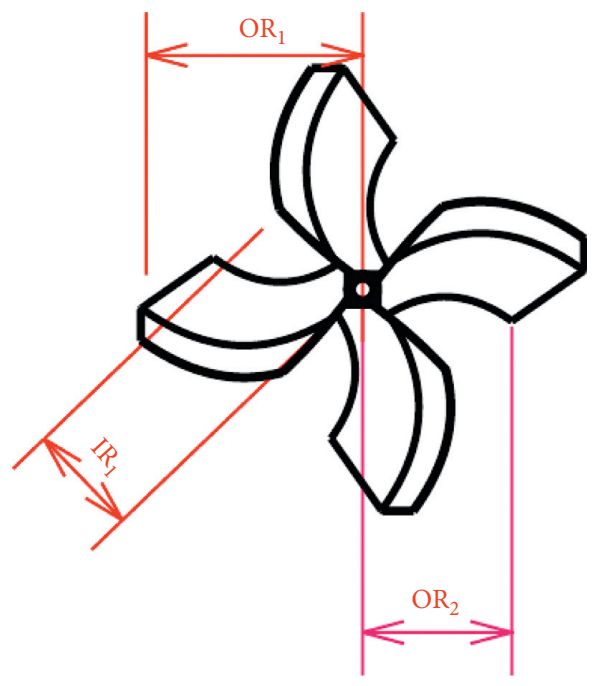

FIGURE 5: Various dimensions in the runner

their effects on turbine performance and power output potential. The flow of parameter study (Figure 4) has been chosen such that nondimensional parameters like angles are studied first. Furthermore, the complexity of parameters for manufacturing has been taken into account while studying the various parameters as well.

Figure 4 shows the order in which the parameters were introduced. Starting with a basic rectangular profile, CFD was employed to find out the efficiencies of the runner at different impact angles, followed by similar methods for blade angles in VP and HP. Experiments followed the resulting trend shown by the numerical simulations. Furthermore, experiments revealed that the water stream was escaping from the gap between the runner blade edge and basin wall. So, the outer edge of the turbine blade was varied to different angles with respect to the turbine shaft, i.e., taper angle. Similarly, the effect of turbine blades' height and blade number was studied.

The power input, shaft power output, and the power coefficient are calculated using equation (1). The power coefficient is plotted against runner speed for the obtained data. For each of the runners, there exists a speed range for which the power output is maximum at the given condition. The performance of all the runners is compared with the efficiency at the best efficiency point:

$$
\begin{aligned}
P_{i} & =\rho Q g h, \\
P_{o} & =T \omega, \\
C_{P} & =\frac{P_{o}}{P_{i}} .
\end{aligned}
$$

\section{Numerical Simulation}

Computational Fluid Dynamics (CFD) is the art of replacing the integrals/partial derivatives in fundamental equations of fluids with discretized algebraic forms, which in turn are solved to obtain numbers for the flow field values at discrete points in time and/or space. All CFD codes contain three main elements: a preprocessor, a solver, and a postprocessor $[27,28]$. CFD facilitates the study of complex flow phenomena without the need for experiments; however, the results need validation against experimental/analytical models before they can be used for design purposes.

The simulation was done on ANSYS Fluent, and 3D modeling of the flow domain was done in CATIA. Multizone meshing, predominantly structured hex, was used. A fully generated mesh of the flow domain is shown in Figure 6. Table 1 shows the solver settings and computer hardware specifications used for simulation. For any CFD result to be less erroneous, it is required that the solution converges and the required solution parameter/s become independent of a number of divisions the fluid domain is divided into [29]. As per mesh independence tests, the number of nodes was set to be around 300,000 (Figure 7). The main assumptions include a steady flow, no-slip conditions on the wall.

SST $k-\omega$ with curvature correction was used for its good behavior in adverse pressure gradients, rotating and separating flow. Furthermore, it provides robustness with lesser computational time than the Reynolds Stress Model for vortical flow simulation [20], since the SST $k-\omega$ model blends $k-\omega$ in the near-wall region and $k-\varepsilon$ in the free stream [30]. Pressurebased segregated solver and implicit scheme were implemented to solve the discretized equation. SIMPLE (SemiImplicit Method for Pressure-Linked Equations) algorithm was implemented for pressure-velocity coupling since it is not computationally expensive and ensures good solution stability. The concept of Multiple Reference Frame (MRF) was implemented in simulation over a range of runner speeds to minimize the computational time required because of the longer computational time required for 22 runners. Studies show that the errors are within acceptable margin when compared to Sliding Mesh (SM) method for turbomachinery simulations [31, 32]. Tonello et al. [32] did a comparative study between SM and MRF approaches for Francis turbine simulation and concluded that SM does not offer a significant advantage over the MRF approach for overall turbine characteristics prediction. Gullberg and Sengupta [31] also suggest that the MRF technique can provide an accurate prediction of turbomachinery performance. Both of the studies conclude that the SM approach is more accurate than the MRF approach; however, turbine/pump performance can be accurately predicted by MRF alone. Also, SM is more useful for understanding flow regimes, pressure fluctuation, etc. in the vicinity of the impeller. Thus, MRF was chosen for this study to predict turbine performance considering the time factor required for simulations.

\section{Experimental Study}

In this study, the basin parameters like dimensions of basin, canal, shaft, and hub have been adapted from [18, 19] whereas flow parameters like head and flow rate were kept unchanged throughout the study. The study was done at a gross head of $0.27 \mathrm{~m}$ and a flow rate of $0.0065 \mathrm{~m}^{3} / \mathrm{s}$ which represents a scaled-down model of the power plant. 


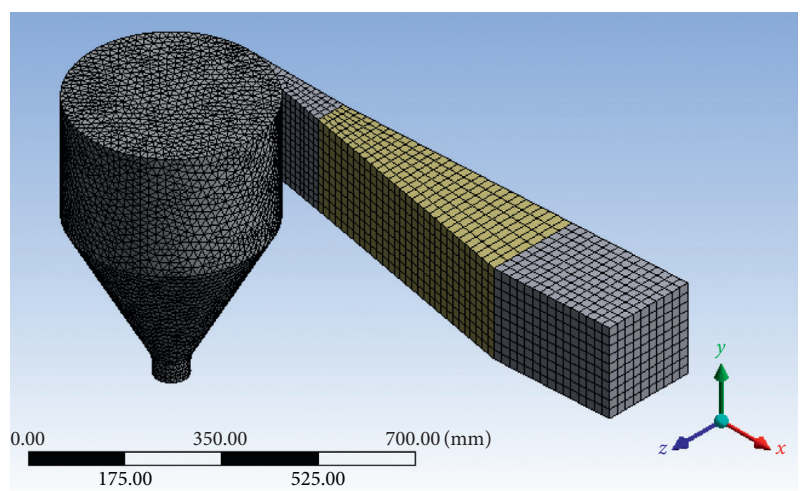

Figure 6: Mesh of flow domain (a coarser mesh shown for easy visualization; actual mesh used for simulation is denser than the mesh displayed).

TABLE 1: Solver settings used for simulation.

\begin{tabular}{lc}
\hline Solver & Steady-state $3 \mathrm{D}$, pressure based \\
\hline $\begin{array}{l}\text { Discretization } \\
\text { scheme }\end{array}$ & Second order in space \\
\hline Turbulence model & SST $k-\omega$ \\
\hline Convergence criteria & RMS, scaled residual target $=10^{-4}$ \\
\hline Computer hardware & Intel Core i7 @ $\begin{array}{c}3.6 \mathrm{GHz} \times 8 \text { cores, } 16 \mathrm{~GB} \\
\text { RAM }\end{array}$ \\
\hline
\end{tabular}

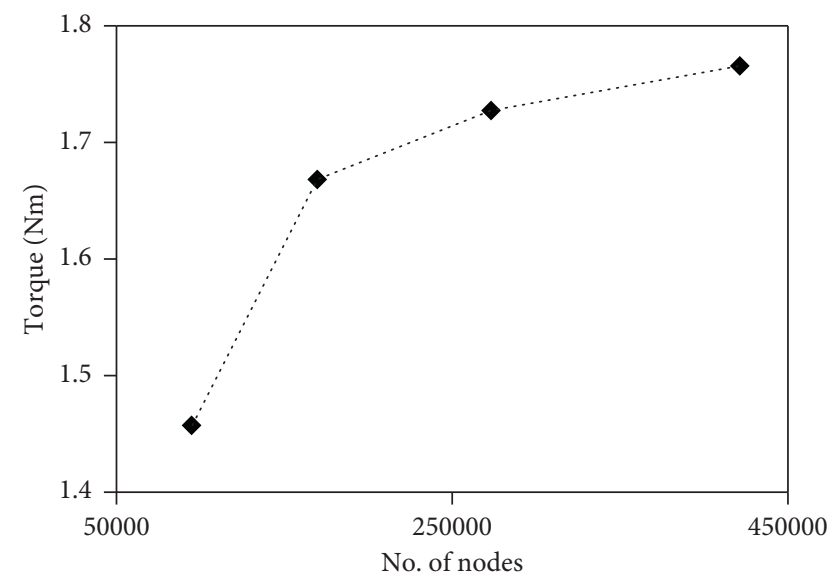

FIgURE 7: Study for mesh independence.

4.1. Test Rig and Runner. The test rig (Figure 8) is a conical drop chamber with a top diameter of $400 \mathrm{~mm}$ and an exit hole diameter of $60 \mathrm{~mm}$. The total height of the basin is $610 \mathrm{~mm}$ and the setup runs on the flow rate of $0.0065 \mathrm{~m}^{3} / \mathrm{s}$. The water is fed through a submersible type centrifugal pump at flow discharge (Q) of $0.009 \mathrm{~m}^{3} / \mathrm{s}$ and head $(H) 9 \mathrm{~m}$. The water reaches the conical basin tangentially through a canal having a notch of $13^{\circ}$ at the side connecting the conical basin inlet. The gate valve is used to maintain the designed flow rate of the system. The water exits from the exit hole and drops down to the doublechambered water tank. With a $90^{\circ} \mathrm{V}$-notch between the chamber,s flow rate is measured. The vertical axis runner is fixed on the shaft of $20 \mathrm{~mm}$ diameter, which is supported by

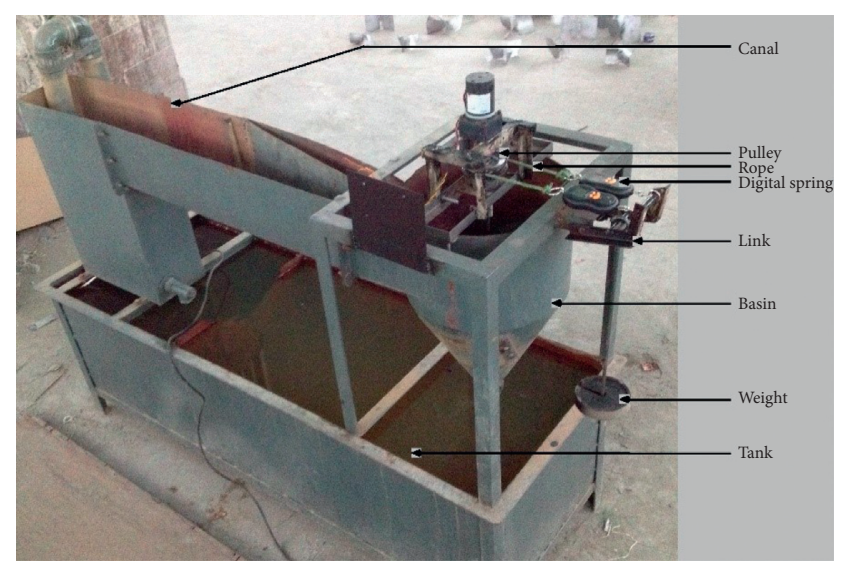

Figure 8: Lab setup.

thrust bearing and guide bearing placed at the top and bottom of the shaft, respectively. The runner is placed concentric to the basin and is at a depth $65 \%$ of the total height from the top of the basin [19]. The runner has blades attached to a hub whose outer diameter $\left(D_{h}\right)$ is $40 \mathrm{~mm}$. Introducing seven different geometrical parameters changes the runner shape and size albeit some dimensions do not change. In Figure $5, \mathrm{OR}_{2}$ is limited by basin dimension whereas the other two are varied by different parameters.

4.2. Torque, Speed, and Flowrate Measurement. A rope brake dynamometer (Figure 9) is used to measure the torque produced by the turbine. It works on the theory that braking torque equals the torque produced by a runner when it attains a steady rotational speed. So, two digital spring balances are present on either side of the cord to determine the amount of tension on each side of the cord. The readings on the digital spring balance and the pulley radius are used to calculate the braking force and thus braking torque on the runner shaft pulley using

$$
\begin{aligned}
& F=g\left(W_{\text {high }}-W_{\text {low }}\right), \\
& T=F\left(\frac{D+d}{2}\right) .
\end{aligned}
$$

$W_{\text {high }}$ and $W_{\text {low }}$ are the kg weight obtained from digital balance reading on high tension side and low tension side, respectively. $D$ and $d$ are the diameters of the pulley and rope, respectively.

A digital tachometer (CHECKLINE CDT-2000HD) is used to measure the rotational speed of the output shaft. The flow is measured using a V-notch and a flowmeter (GEOPACKS ZMFP51) simultaneously, and finally, the average of both data is taken for further calculation. The amount of fluid flowing through a V-notch is measured by [33]

$$
Q_{\text {notch }}=1.38 * h^{2.5} \text {. }
$$

4.3. Accuracy of Instruments. The accuracy of all of the measuring instruments used throughout the experiment is listed in Table 2 based on the least count of corresponding instruments. 
TABLE 2: Accuracy of measuring instrument.

\begin{tabular}{lcc}
\hline Instrument & Least count & Error \\
\hline Ruler & $1 \mathrm{~mm}$ & $\pm 1 \mathrm{~mm}$ \\
Vernier caliper & $0.05 \mathrm{~mm}$ & $\pm 0.05 \mathrm{~mm}$ \\
Digital balance & $1 \mathrm{gm}$ & $\pm 10 \mathrm{gm}$ \\
Tachometer & $0.01 \mathrm{RPM}$ & $0.01 \mathrm{RPM}$ or $\pm 0.02 \%$ \\
Flowmeter & $0.01 \mathrm{~m} / \mathrm{s}$ & $0.01 \mathrm{~m} / \mathrm{s}$ or $\pm 2 \%$ \\
V-notch & - & $\pm 2 \%$ \\
\hline
\end{tabular}

\section{Results and Discussion}

This section presents the results obtained from simulations and experiments. Figure 10 shows the various runners manufactured for the study. The performance curves of 22 different runners are presented in Section 7. The curves are plotted with the power coefficient on the vertical axis and rotational speed on the horizontal axis. For each of the runners, the power coefficient increases with speed and then decreases. So, the point of the maximum performance of each of the runners has been passed into a runner data set (Set 1-Set 7).

Table 3 shows the different parameters value, their optimum value, errors among experiment and simulation, and the order of study. All of the seven-runner data set has been approximated using a second-degree polynomial curve fit. The equations are shown alongside each curve. This helps in the rough estimation of the maximum power coefficient and the corresponding value of the parameter for the maximum power coefficient, tabulated in Table 3 as the optimum value. The optimum value from each set is identified and applied in modeling successive runner sets. The optimum impact angle determined from Set 1 is passed on to successive sets and so on. However, owing to the precision difficulties in local manufacturing, the optimum values have been rounded off to make consistent intervals in parameter values for each set. Thus, a total of 22 runners have been modeled, manufactured, and tested. These runners (R1-R22) have been divided into seven sets (Table 3) with four models in each set on the basis of parameters varied with recurrence of R3, R9, R12, R15, and R18 in more than one set.

The results of the parameter height and cut have been presented here in a nondimensional form as height ratio and cut ratio simultaneously:

$$
\begin{aligned}
\text { height ratio } & =\frac{\text { runner height }}{\text { basin height }}, \\
\text { cut ratio } & =\frac{\mathrm{IR}_{1}-\left(D_{h} / 2\right)}{\mathrm{OR}_{1}-\left(D_{h} / 2\right)} .
\end{aligned}
$$

Experiments agree with the computational results for each of the runner sets. The tendency seen is an increase up to a maximum value followed by a decrease (Figures 11 and 13-17) in power coefficient for all the parameters except blade angles in VP (Figure 12) which records only a decrease in power production ability.

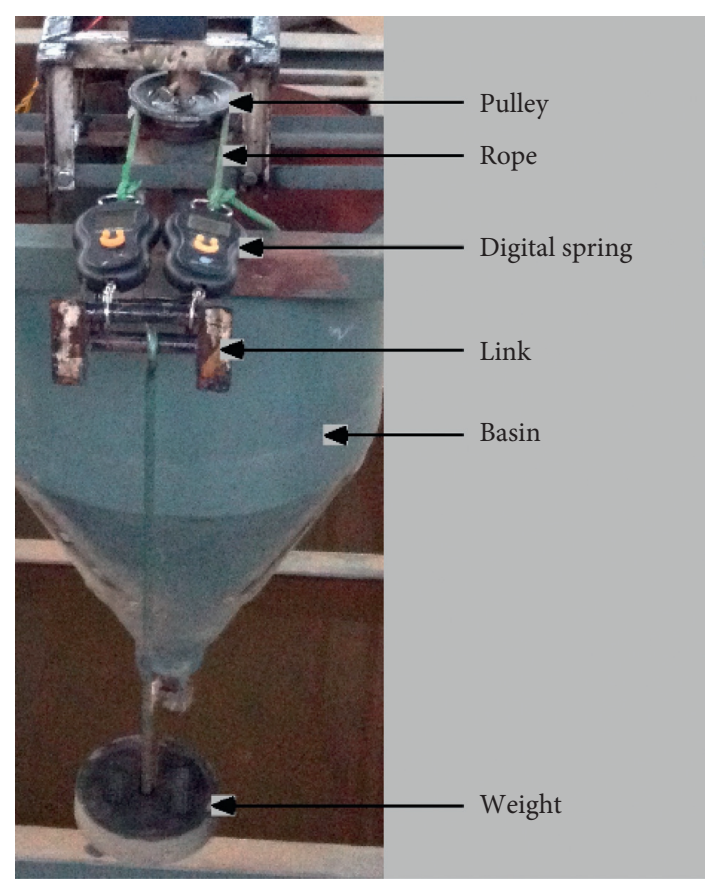

Figure 9: Dynamometer.

Introducing a suitable impact angle helps with perpendicular impact from the incoming water stream. This effect is positive until $20^{\circ}$; at that point the runner attains maximum power coefficient among Set 1 runners. Introducing blades' angle in VP eventually disturbs the vortex formation and thus decreases the power coefficient with an increase in blade angle. The blade angle introduced in HP does not disturb vortex formation unlike the blade angle in VP. With an increasing taper angle, the geometrical nature of both the basin and runner happens to be the same, i.e., conical, and this decreases water seepage from the sides of the runner. However, some clearance is still required to maintain the circulation of water around the basin, which causes some decrease in efficiency at a lower taper angle. The height ratio is the most influential parameter since the blade surface area changes rapidly with a change in height. The power coefficient tends to decrease at a higher height ratio since water drag and runner weight start dominating the power production capacity of the runner. The trimming of the inner part on the top portion of the blade with the introduction of the cut ratio is a productive approach. It is probably due to the decrease in runner weight since the cut portion does not come in contact with the water stream more often. The removed portion in the blade slightly changes the outlet blade angle on the blade top half, and the water stream exiting that edge does not disturb the vortex motion. On the other hand, when a large portion of the blade is cut, i.e., the cut ratio increased, the effective surface area of the runner blade decreases which caused a decrease in power coefficient. The runner with 5 blades has the highest power coefficient. The increment of the blade number makes the runner capable of handling a large amount of flow efficiently. The frequency at which the incoming fluid strikes the runner increases. The negative effect of using more blades in a single 


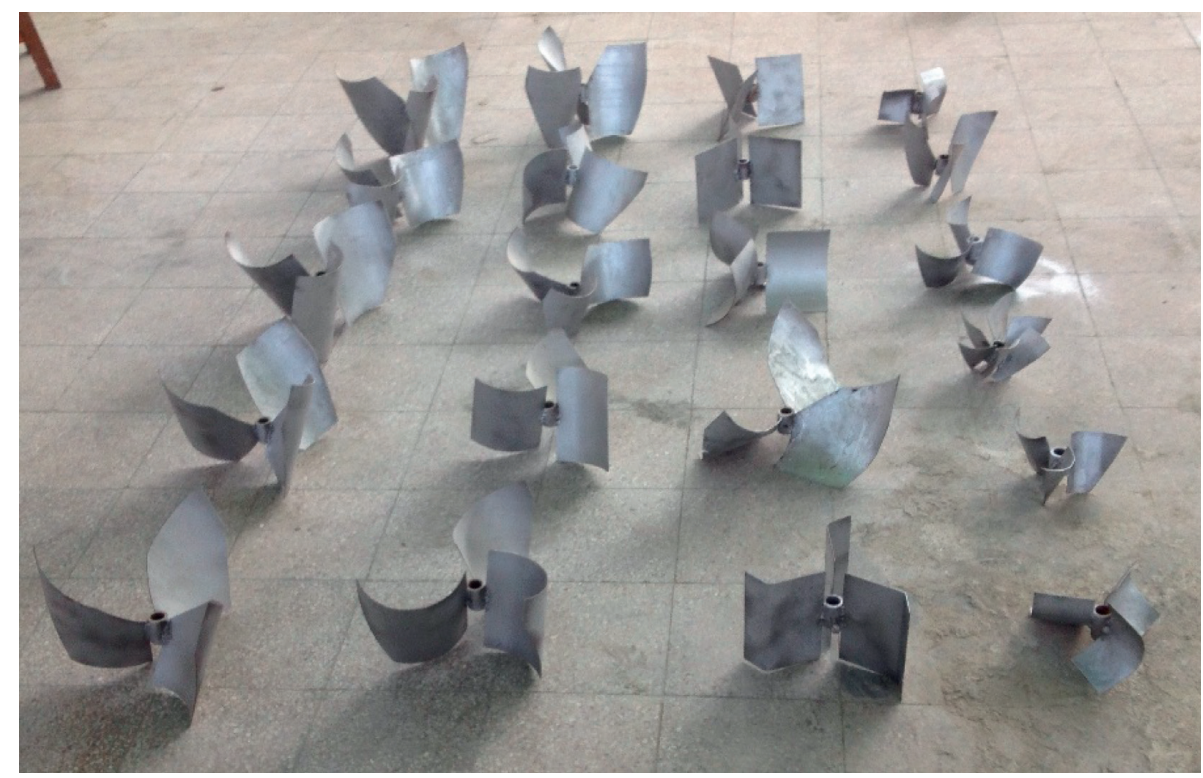

FIGURE 10: Runners used for the study.

TABLE 3: Runner sets with their design parameter values and optimum values.

\begin{tabular}{|c|c|c|c|c|c|c|c|}
\hline \multirow{2}{*}{ Runner set and parameter } & \multirow{2}{*}{ Runner } & \multirow{2}{*}{ Design value } & \multicolumn{2}{|c|}{ Maximum $C_{p}$} & \multicolumn{3}{|c|}{ Optimum $C_{p}{ }^{a}$} \\
\hline & & & $\operatorname{Exp}^{\mathrm{b}}$ & Comp $^{c}$ & $\operatorname{Exp}^{\mathrm{b}}$ & Comp $^{c}$ & $\%$ error $^{\mathrm{d}}$ \\
\hline \multirow{4}{*}{ Set 1-impact angle } & $\mathrm{R} 1$ & $0^{\circ}$ & 0.2902 & 0.4637 & \multirow{4}{*}{$18^{\circ}$} & \multirow{4}{*}{$19^{\circ}$} & \multirow{4}{*}{5.55} \\
\hline & $\mathrm{R} 2$ & $10^{\circ}$ & 0.2977 & 0.4804 & & & \\
\hline & R3 & $20^{\circ}$ & 0.3082 & 0.4886 & & & \\
\hline & $\mathrm{R} 4$ & $30^{\circ}$ & 0.2953 & 0.4756 & & & \\
\hline \multirow{4}{*}{ Set 2-inlet/outlet blade angle in VP } & R3 & $0^{\circ}$ & 0.3082 & 0.4886 & \multirow{4}{*}{$0^{\circ}$} & \multirow{4}{*}{$0^{\circ}$} & \multirow{4}{*}{0} \\
\hline & R5 & $20^{\circ}$ & 0.2938 & 0.4688 & & & \\
\hline & R6 & $40^{\circ}$ & 0.2816 & 0.4474 & & & \\
\hline & R7 & $60^{\circ}$ & 0.2732 & 0.438 & & & \\
\hline \multirow{4}{*}{ Set 3-inlet/outlet blade angle in HP } & R3 & $90^{\circ}$ & 0.3082 & 0.4886 & \multirow{4}{*}{$60^{\circ}$} & \multirow{4}{*}{$52^{\circ}$} & \multirow{4}{*}{13.33} \\
\hline & $\mathrm{R} 8$ & $70^{\circ}$ & 0.3231 & 0.4976 & & & \\
\hline & R9 & $50^{\circ}$ & 0.3296 & 0.5149 & & & \\
\hline & $\mathrm{R} 10$ & $30^{\circ}$ & 0.3113 & 0.4935 & & & \\
\hline \multirow{4}{*}{ Set 4-taper angle } & R9 & $0^{\circ}$ & 0.3296 & 0.5149 & \multirow{4}{*}{$28^{\circ}$} & \multirow{4}{*}{$23^{\circ}$} & \multirow{4}{*}{17.85} \\
\hline & $\mathrm{R} 11$ & $10^{\circ}$ & 0.3479 & 0.5379 & & & \\
\hline & $\mathrm{R} 12$ & $20^{\circ}$ & 0.3993 & 0.5685 & & & \\
\hline & $\mathrm{R} 13$ & $30^{\circ}$ & 0.3876 & 0.5568 & & & \\
\hline \multirow{4}{*}{ Set 5-height ratio } & $\mathrm{R} 12$ & 0.27 & 0.3993 & 0.5685 & \multirow{4}{*}{0.315} & \multirow{4}{*}{0.32} & \multirow{4}{*}{1.59} \\
\hline & $\mathrm{R} 14$ & 0.31 & 0.4052 & 0.5813 & & & \\
\hline & $\mathrm{R} 15$ & 0.35 & 0.409 & 0.594 & & & \\
\hline & $\mathrm{R} 16$ & 0.39 & 0.3888 & 0.5529 & & & \\
\hline \multirow{4}{*}{ Set $6-$ cut ratio } & R15 & 0 & 0.409 & 0.594 & \multirow{4}{*}{0.13} & \multirow{4}{*}{0.15} & \multirow{4}{*}{15.38} \\
\hline & $\mathrm{R} 17$ & 0.1 & 0.4166 & 0.6059 & & & \\
\hline & $\mathrm{R} 18$ & 0.2 & 0.4325 & 0.615 & & & \\
\hline & R19 & 0.3 & 0.3899 & 0.591 & & & \\
\hline \multirow{4}{*}{ Set 7-number of blades } & $\mathrm{R} 18$ & 3 & 0.4325 & 0.615 & & & \\
\hline & $\mathrm{R} 20$ & 4 & 0.4603 & 0.6297 & & & \\
\hline & $\mathrm{R} 21$ & 5 & 0.4785 & 0.6402 & 5 & 5 & 0 \\
\hline & $\mathrm{R} 22$ & 6 & 0.4623 & 0.6324 & & & \\
\hline
\end{tabular}

${ }^{a}$ Optimum value obtained from best fitted $2^{\text {nd }}$ degree polynomial curve, Figures $1-17$. These are probabilistic values rather than the actual values obtained from experiment or simulation. ${ }^{\mathrm{b}}$ Experimental data. ${ }^{\mathrm{c}}$ Computational data. ${ }^{\mathrm{d}}$ Calculated taking experimental data as a reference. 

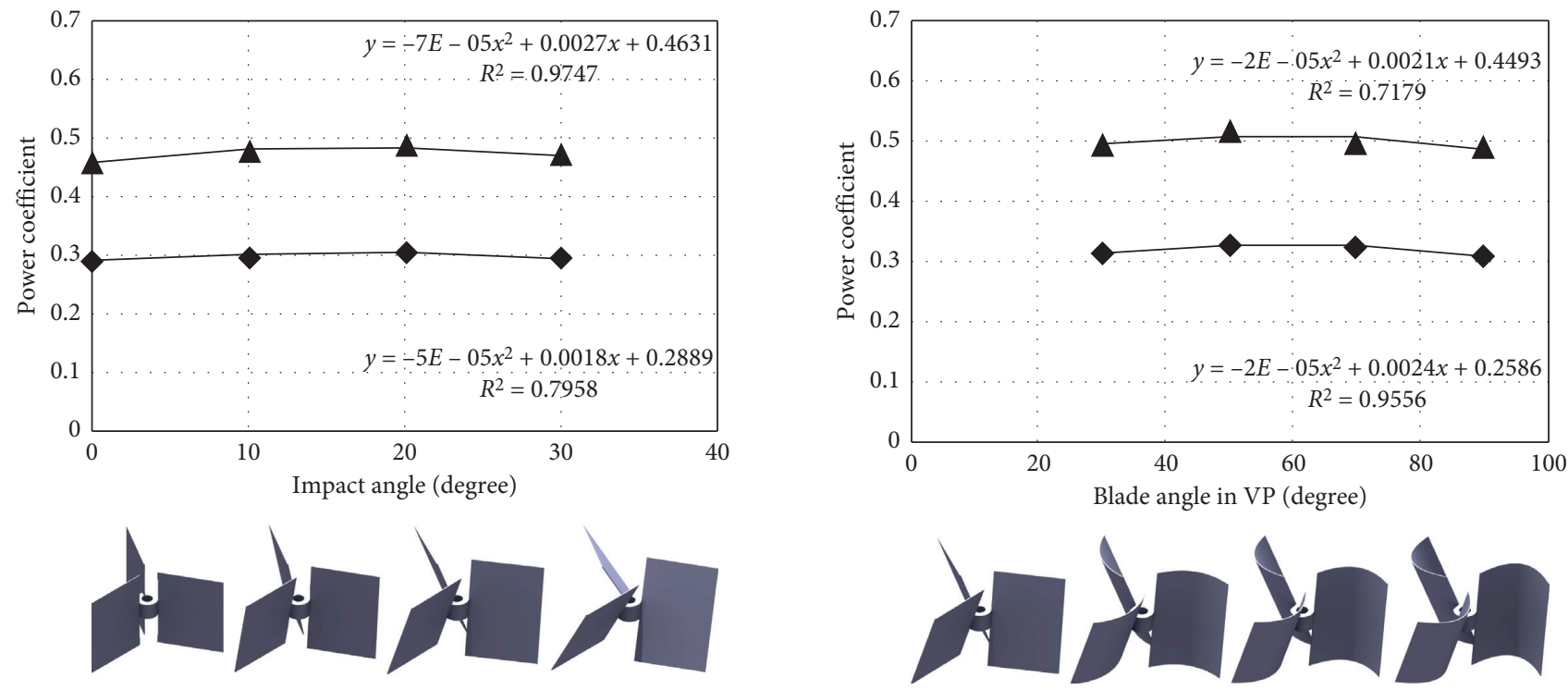

FIGURE 11: Set 1 data points (left to right-runners R1, R2, R3, and $\mathrm{R} 4)$.
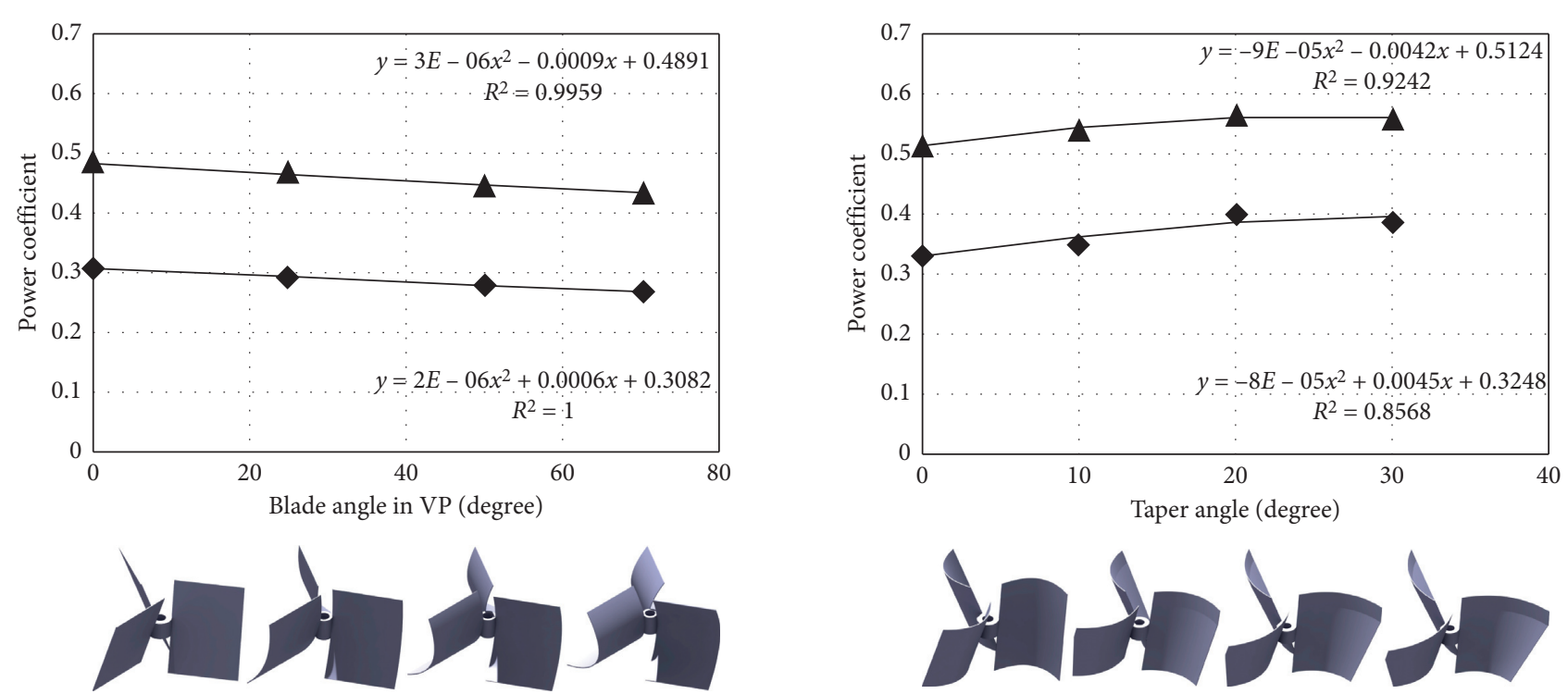

Figure 12: Set 2 data points (left to right-runners R3, R5, R6, and R7).

runner is that the weight of the runner increases along with drag loss.

For similar test conditions, the runner with an impact angle of $20^{\circ}$ shows the highest power coefficient. Computational results show the decrease in power coefficient with an increase in blade angle in VP with a maximum value at $0^{\circ}$ blade angle in VP. Among the runners of Set 3 , the maximum efficiency was achieved for the runner having a blade angle of $50^{\circ}$ in HP. Similarly, the taper angle has a major influence on the efficiency of the runner, found

Figure 13: Set 3 data points (left to right-runners R3, R8, R9, and R10).

IGURE 14: Set 4 data points (left to right-runners R9, R11, R12, and R13).

efficient at $20^{\circ}$, whereas the runner height is found to be the most influential parameter, with the highest power coefficient at the height ratio of 0.35 . The cut ratio of 0.2 shows the optimum condition whereas 5 blades are the most suitable for the maximum power production purpose.

All the optimum values of parameters derived from CFD results and experiments show good conformance with a slight deviation in the blade angle in HP and taper angle. Likewise, the similar nature of the performance curves with consistent error margin suggests that the error is systematic. The error 

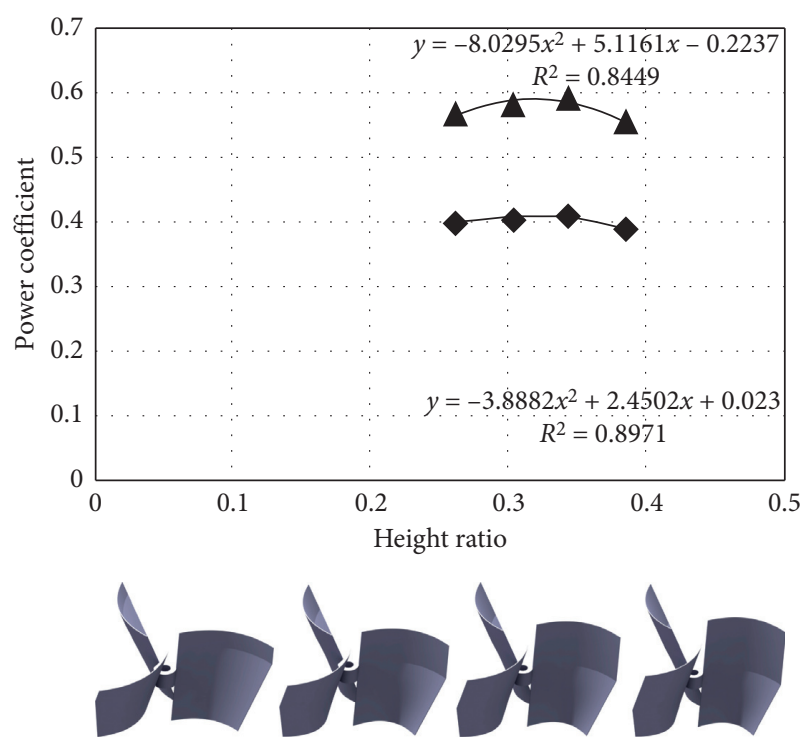

Figure 15: Set 5 data points (left to right-runners R12, R14, R15, and R16).
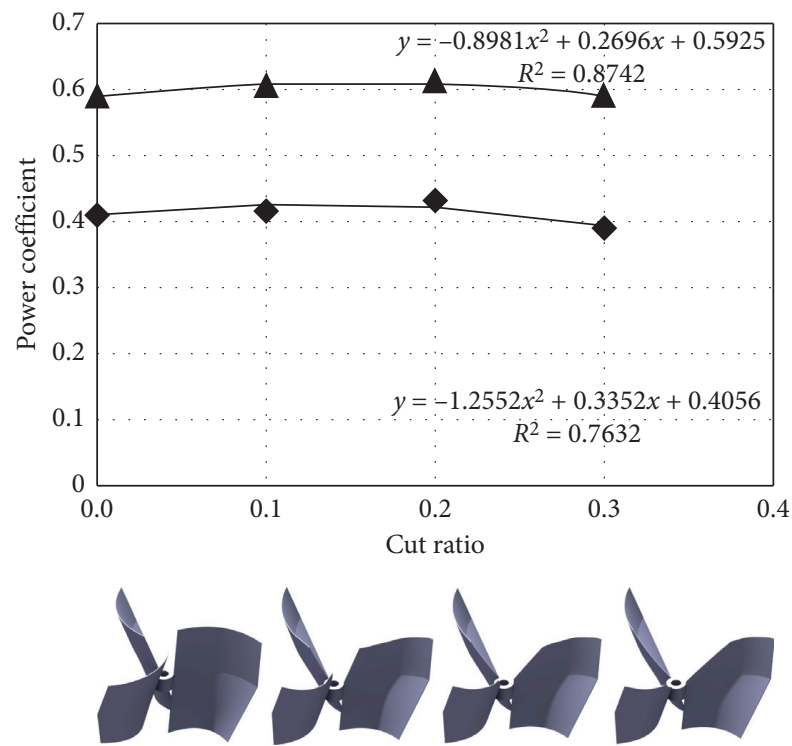

FIGURE 16: Set 6 data points (left to right-runners R15, R17, R18, and R19).

might have occurred due to the assumptions and simplifications made in the computational study, because of the limitation of CFD software to accept all possible factors. Errors are also possible when the exact experiment condition is not replicated in CFD. To get a proper visualization of flow regimes and correctly predict the turbine performance, transient multiphase simulation is necessary, as air-water mixture exists inside the basin, but the requirement of high computational facilities could not be met, which is a likely cause for variation. Moreover, the flow through the canal and basin is open channel flow in the experimental setup, but a close conduit is taken to avoid numerical complexity and reduce simulation
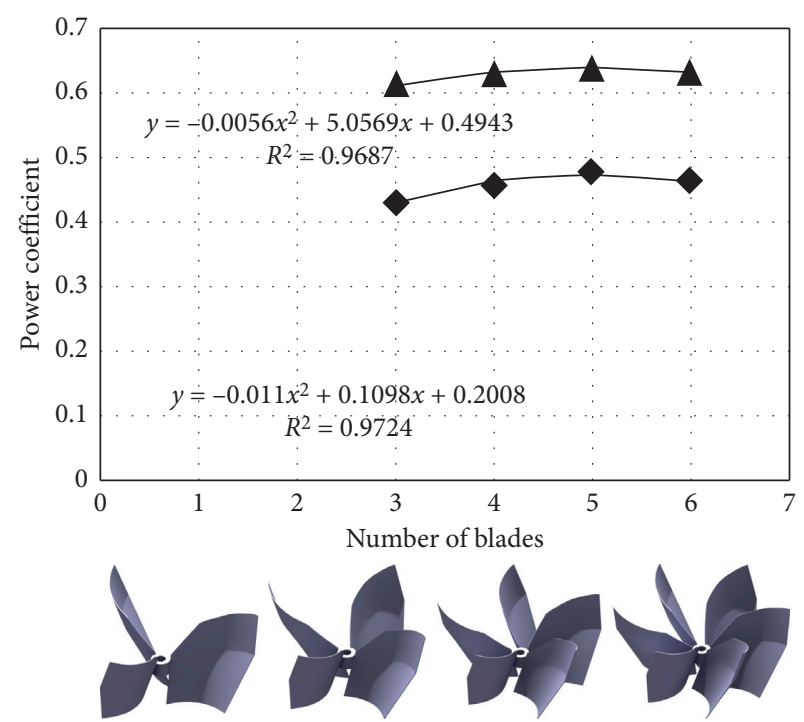

FIgURE 17: Set 7 data points (left to right-runners R18, R20, R21, and R22).

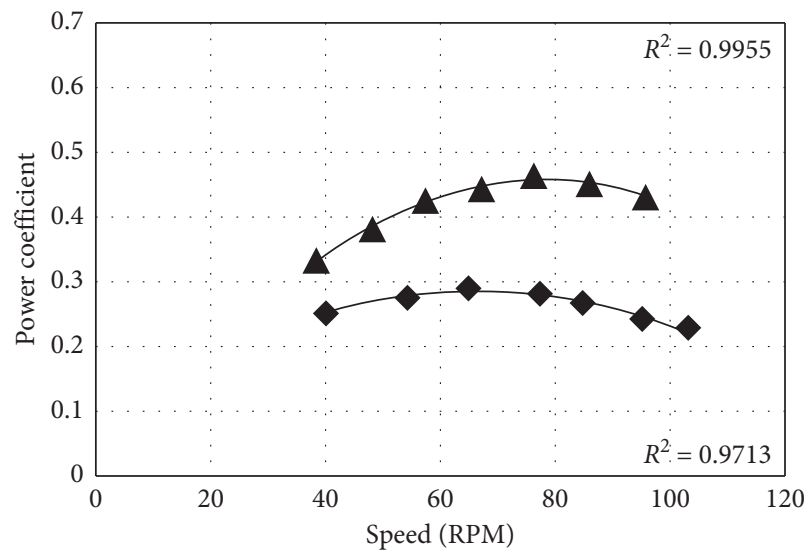

Figure 18: Runner 1 data points.

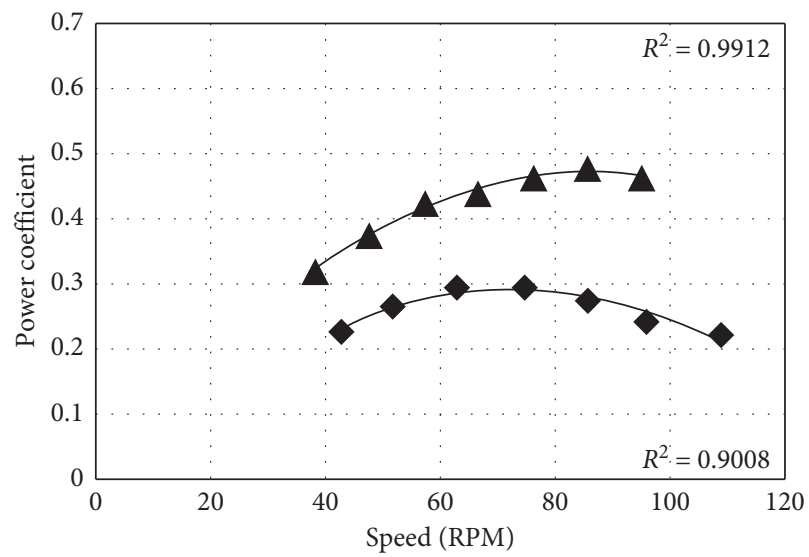

Figure 19: Runner 2 data points. 


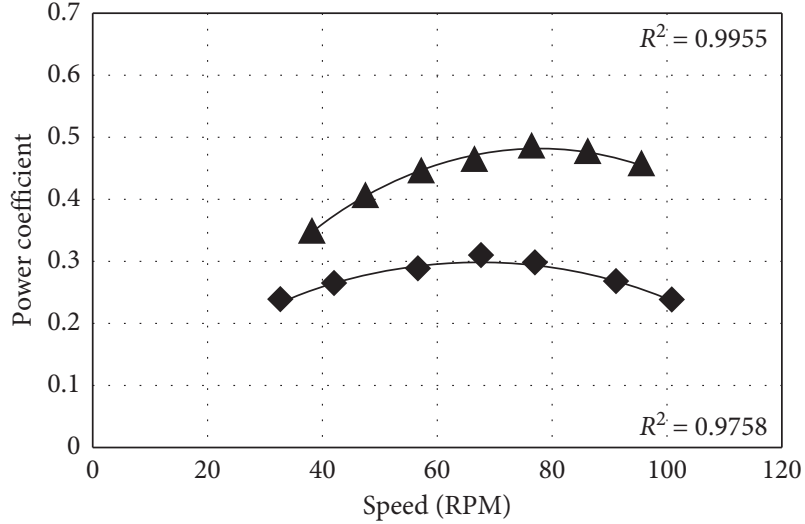

Figure 20: Runner 3 data points.

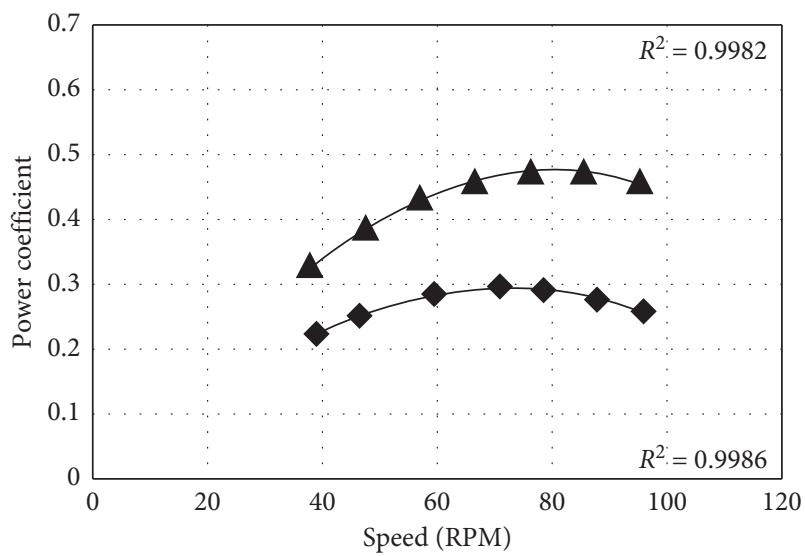

Figure 21: Runner 4 data points.

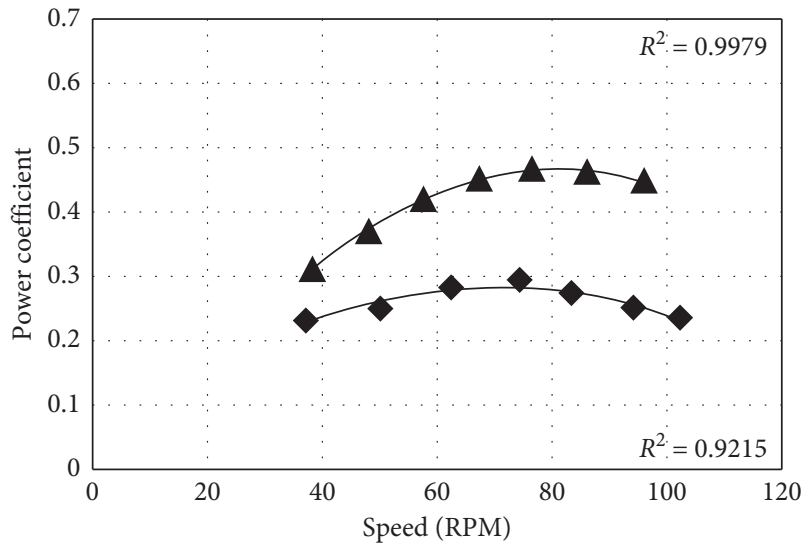

FIGURE 22: Runner 5 data points.

time without heavily sacrificing the accuracy of simulation results. Furthermore, the general causes of the error which are fabrication errors, mechanical losses, torque meter accuracy, leakage, and increased surface friction are major problems encountered during the experimental study. In spite of various

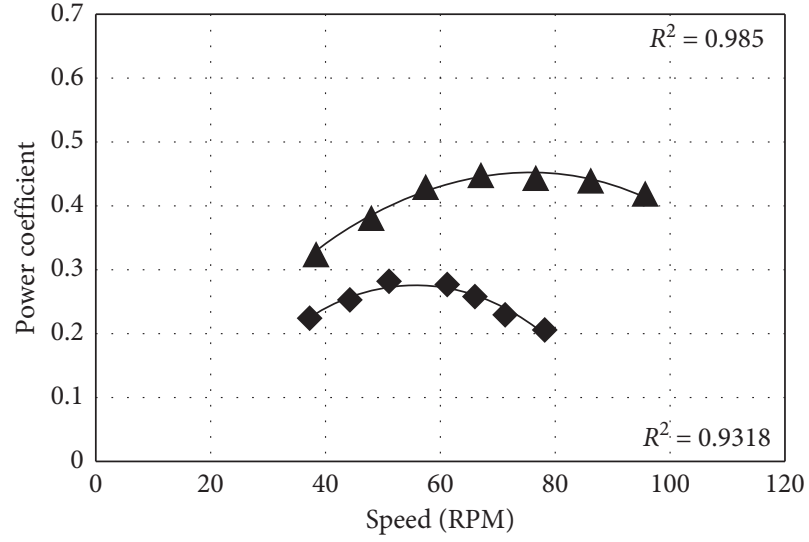

Figure 23: Runner 6 data points.

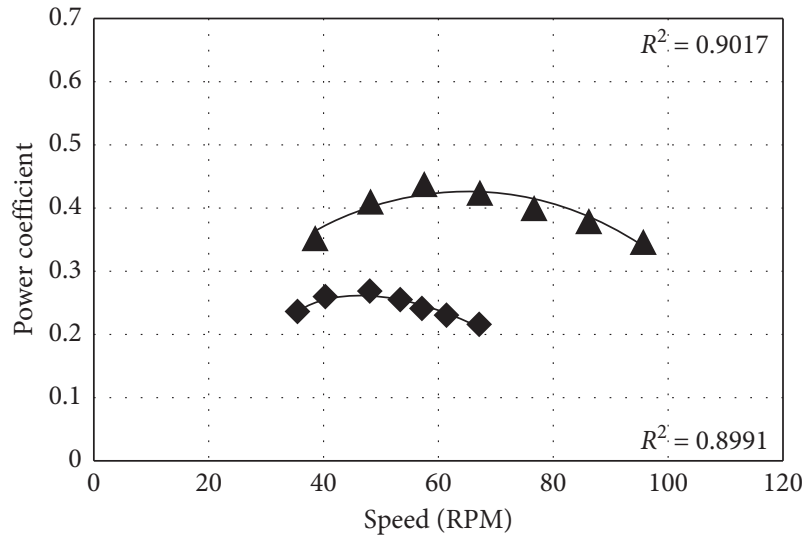

Figure 24: Runner 7 data points.

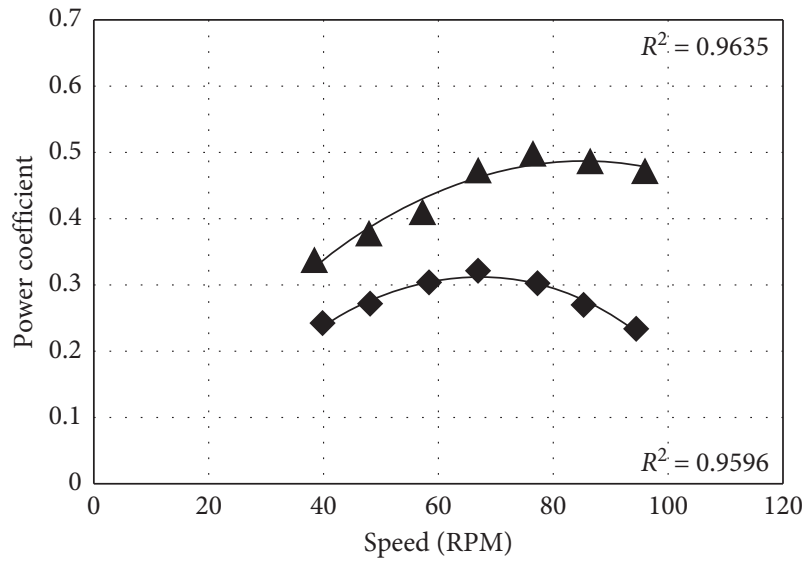

FIGURE 25: Runner 8 data points.

challenges in the study, the data sets obtained from the computational study show a similar trend with the experimental data sets, and the data sets for all runner show analogous deviation. The results obtained from this study could be used as a reference for the design of runners for GWVPP. 


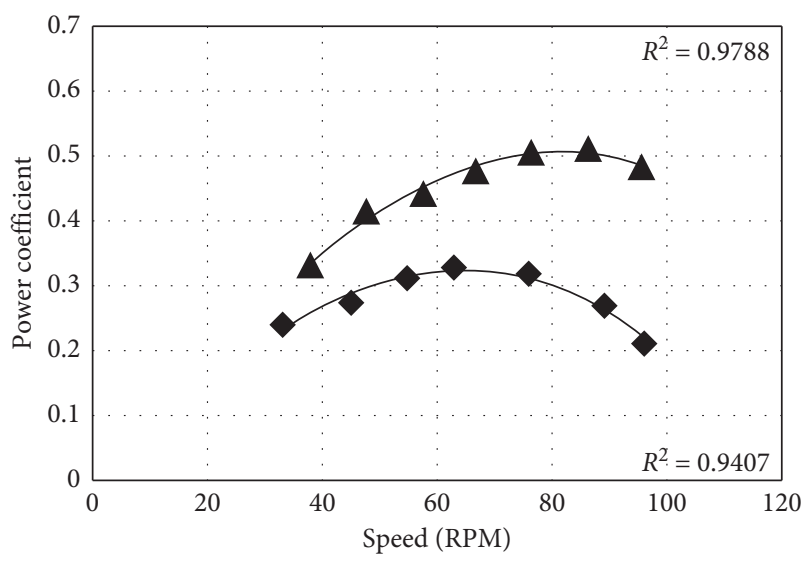

Figure 26: Runner 9 data points.

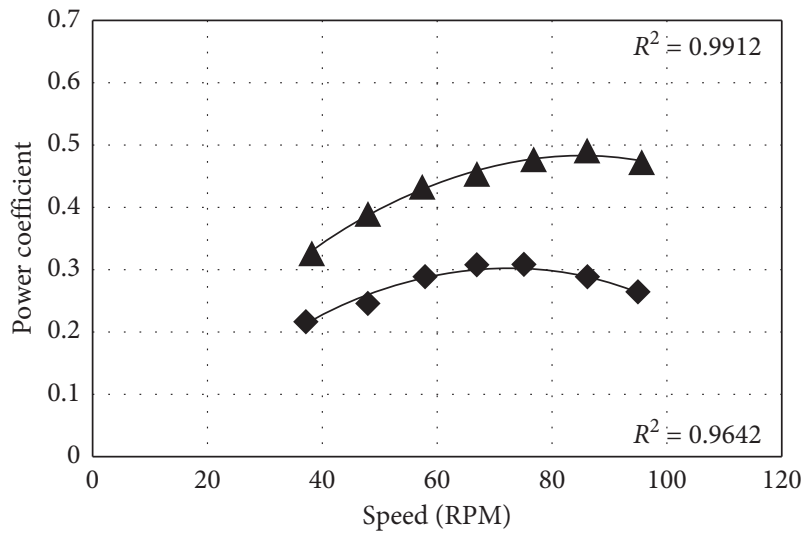

Figure 27: Runner 10 data points.

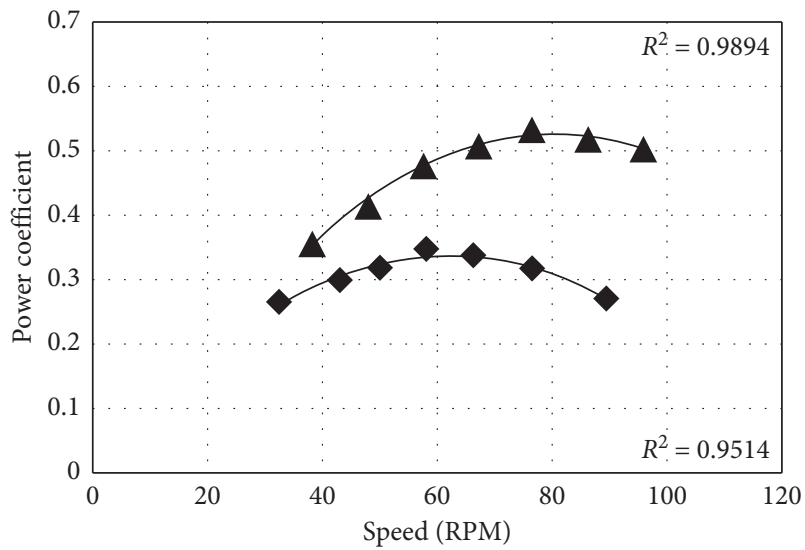

FIgURE 28: Runner 11 data points.

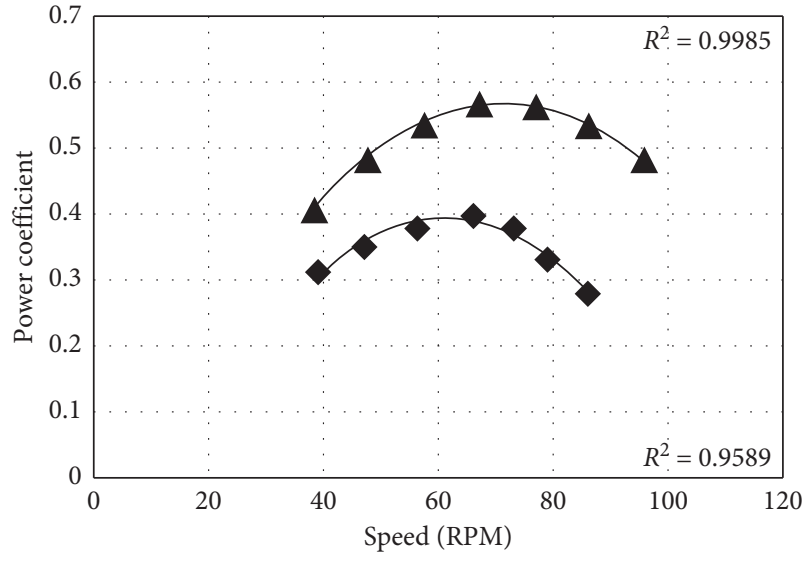

FIgURE 29: Runner 12 data points.

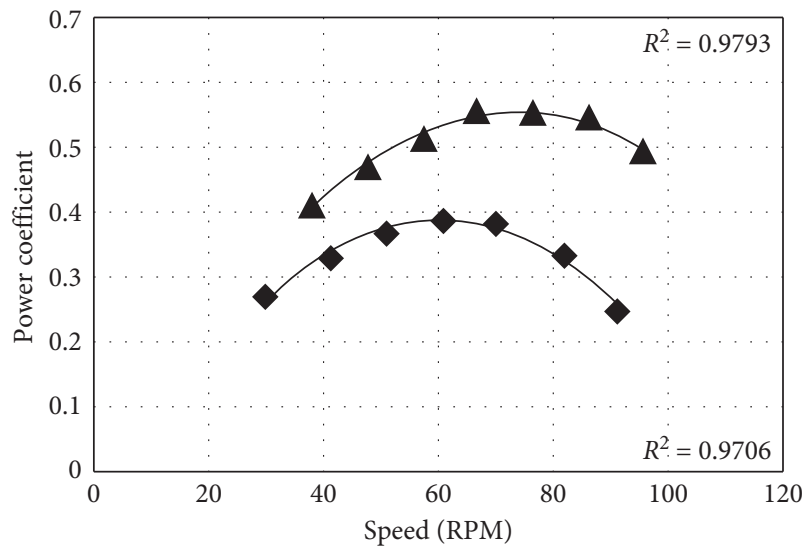

Figure 30: Runner 13 data points.

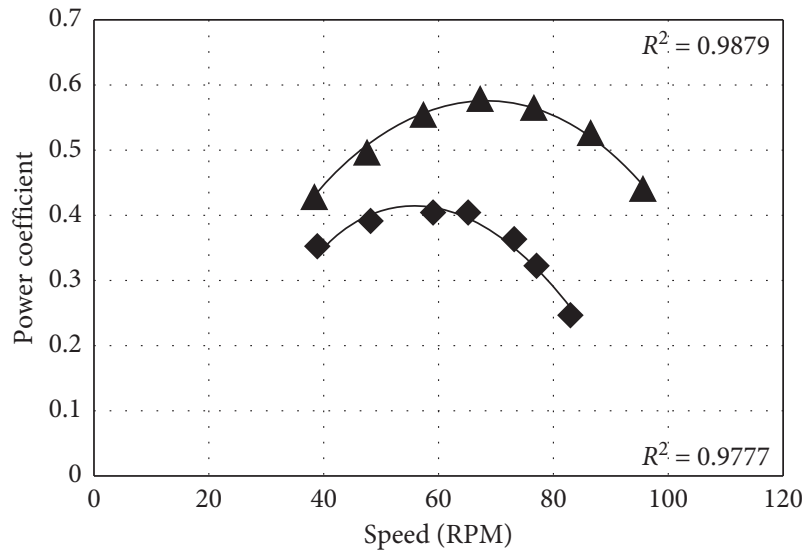

Figure 31: Runner 14 data points. 


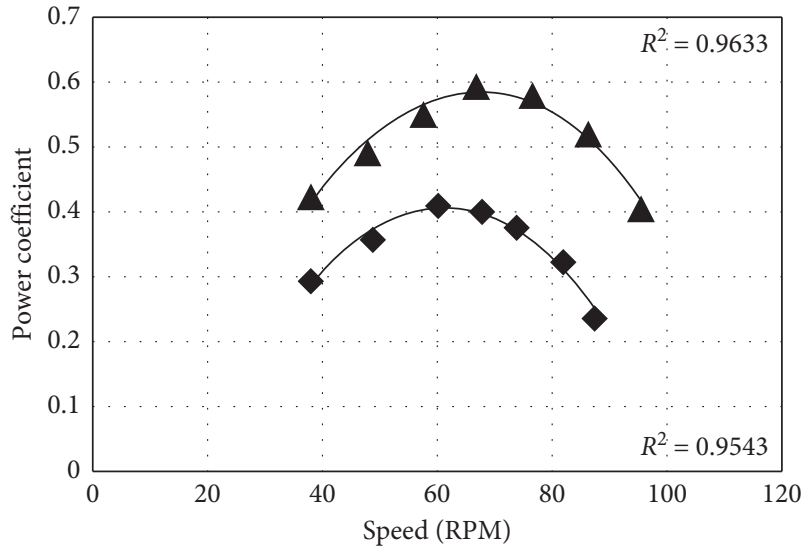

FIgURE 32: Runner 15 data points.

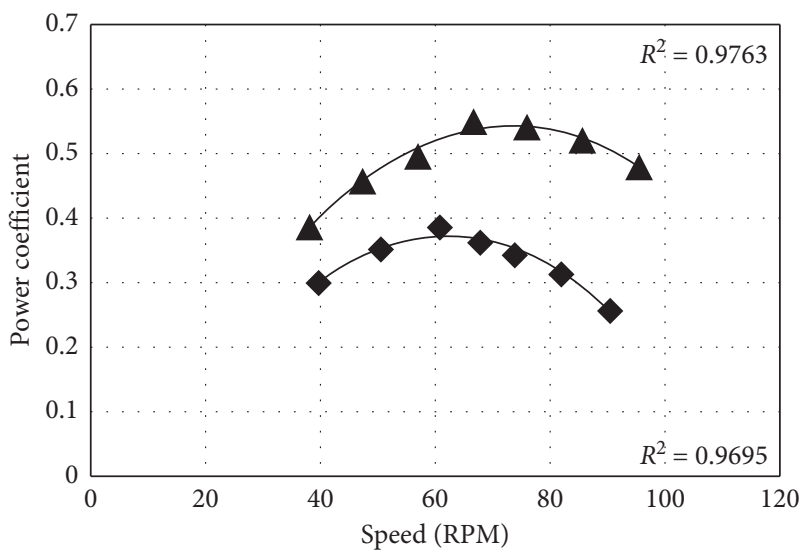

FIgURE 33: Runner 16 data points.

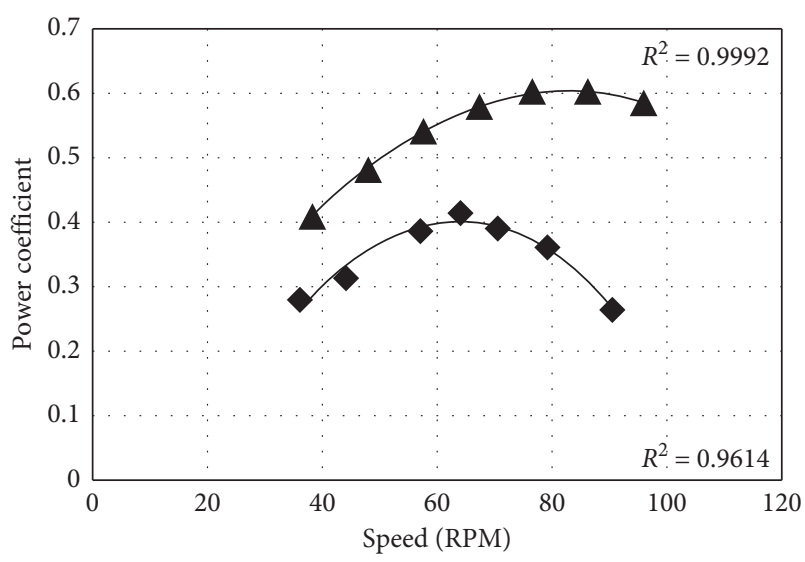

FIgure 34: Runner 17 data points.

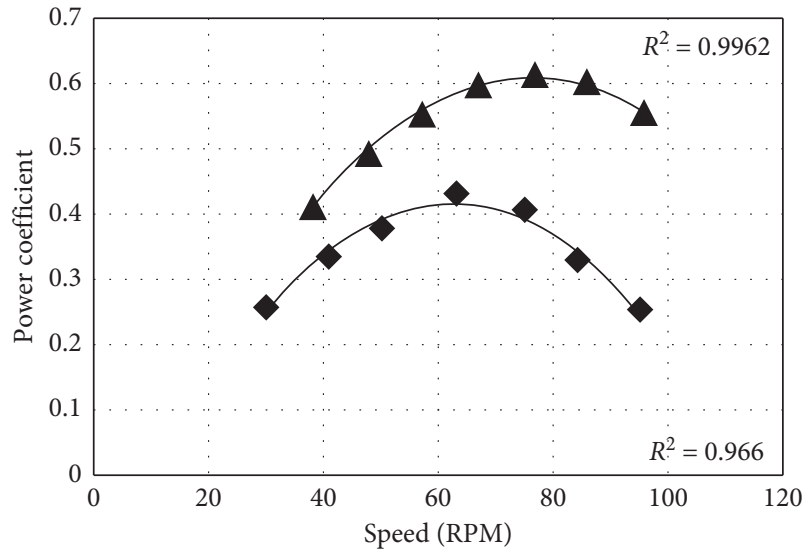

Figure 35: Runner 18 data points.

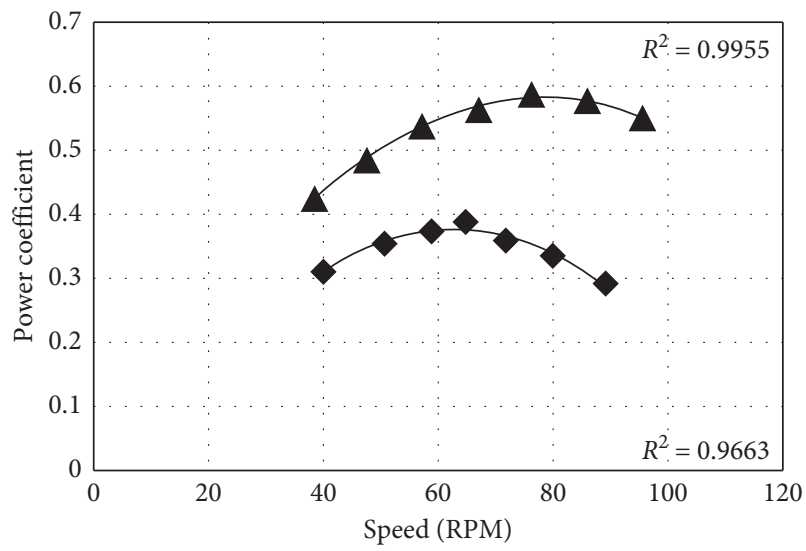

Figure 36: Runner 19 data points.

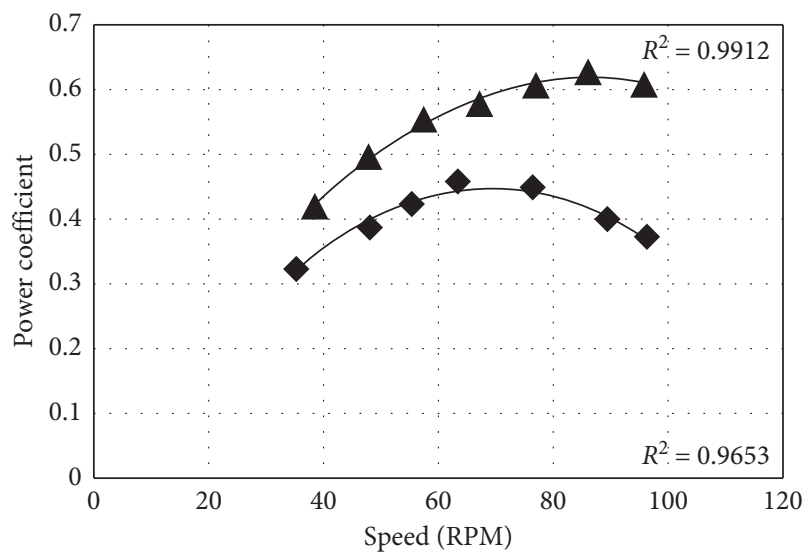

Figure 37: Runner 20 data points. 


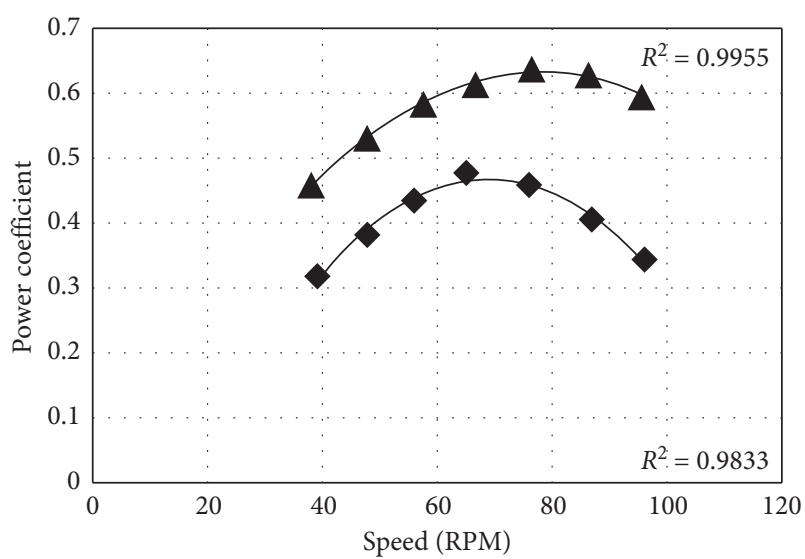

Figure 38: Runner 21 data points.

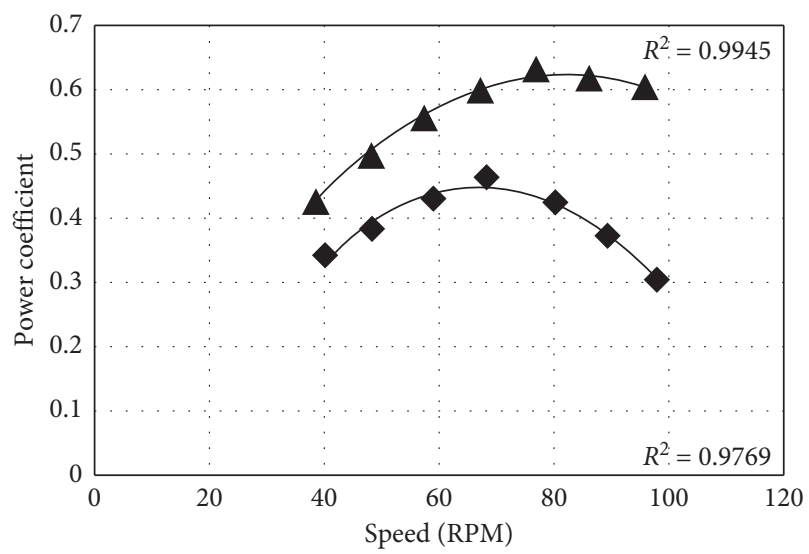

FIgURE 39: Runner 22 data points.

\section{Conclusions}

This study has analyzed the effect of runner design parameters on the system performance of the GWVPP. As indicated by the literature, the operating speed of the runner is 50-80 RPM, and hence, the study of torque was carried out in this speed range. The study of geometrical parameters is done with the help of CFD and compared with the results of laboratory experiments. The several parameters used in the design of the runner are impact angle, blade angles in VP and HP, taper angle, height, cut, and the number of blades. For each of the parameters varied, the power coefficient change is small. The bigger picture is only visible when the range of power coefficient is determined since each of the parameters has a small contribution to increasing the turbine power coefficient. The height ratio is the parameter to be most cared for since this affects the power coefficient largely. The efficiency of the Gravitational Water Vortex Turbine (GWVT) can be improved by the selection of optimum geometrical parameters. Here, the power coefficient has been increased to 0.64 as obtained from simulation and 0.478 as obtained from experiments. The efficiency of the turbine for the conical basin has been increased to an acceptable margin for commercialization of the Water Vortex Turbine as a pico-hydro system. So, in designing a runner for GWVPP with conical basins, the following points shall be recommended:

(1) Runner height to basin height ratio of $0.31-0.32$

(2) Taper angle conforming the basin cone angle and impact angle of $20^{\circ}$

(3) Blades should be curved when viewed from the top only with blades angle within $50^{\circ}-60^{\circ}$ range

(4) A cut ratio of no more than $15 \%$

Any of the recommended configurations do not require any sophisticated manufacturing plant and thus can be manufactured locally with the help of basic sheet metal skills. This makes the deployment cost less and easier. Thus, GWVPP is a viable and cost-effective option for the picohydro system in developing countries. However, a study approach based on vortex flow theory on the conical basin, multiphase simulations can improve understanding of the system and help in determining a more suitable turbine for the system.

\section{Runner Performance Curves}

The performance curves of 22 individual runners have been presented in this section (Figures 18-39). The power coefficient has been plotted in the $y$-axis against the runner speed on the $\mathrm{x}$-axis.
Abbreviations
SST: $\quad$ Shear stress transport
CFD: $\quad$ Computational fluid dynamics
RPM: $\quad$ Revolution per minute
GWVPP: Gravitational water vortex power plant
GWVT: Gravitational water vortex turbine
GWV: Gravitational water vortex
VP: $\quad$ Vertical plane $(x-y$ or $y-z$ plane $)$
HP: $\quad$ Horizontal plane ( $x-z$ plane)
MRF: $\quad$ Multiple reference frame
SM: $\quad$ Sliding mesh
SIMPLE: Semi-Implicit Method for Pressure-Linked
PV: $\quad$ Photovoltaic.

\section{Symbols}

$\begin{array}{ll}r: & \text { Radial component of velocity } \\ \theta: & \text { Tangential component of velocity } \\ z: & \text { Axial component of velocity } \\ P_{i}, P_{o}: & \text { Input, output power }(W) \\ \rho: & \text { Mass density }\left(\mathrm{kg} / \mathrm{m}^{3}\right) \\ g: & \text { Acceleration due to gravity }\left(\mathrm{m} / \mathrm{s}^{2}\right) \\ Q: & \text { Volume flow rate }\left(\mathrm{m}^{3} / \mathrm{s}\right) \\ H: & \text { Head }(\mathrm{m}) \\ h: & \text { Height of water level in } \mathrm{V} \text {-notch }(\mathrm{m}) \\ T: & \text { Torque }(\mathrm{N} \cdot \mathrm{m}) \\ \bar{\omega}: & \text { Angular velocity }\end{array}$




\begin{tabular}{|c|c|}
\hline$k:$ & Turbulent kinetic energy $(\mathrm{J} / \mathrm{kg})$ \\
\hline$\omega:$ & $\begin{array}{l}\text { Specific rate of dissipation of turbulent kinetic } \\
\text { energy }(1 / \mathrm{s})\end{array}$ \\
\hline$\varepsilon:$ & $\begin{array}{l}\text { Rate of dissipation of turbulent kinetic energy } \\
(\mathrm{J} / \mathrm{kg} \cdot \mathrm{s})\end{array}$ \\
\hline$C_{p}:$ & Power coefficient \\
\hline$D_{p}:$ & Diameter of the pulley groove $(\mathrm{m})$ \\
\hline$D_{h}^{P}:$ & Hub diameter $(\mathrm{m})$ \\
\hline$d:$ & Diameter of braking rope $(\mathrm{m})$ \\
\hline $\mathrm{IR}_{1}:$ & $\begin{array}{l}\text { Inner radius of the runner at the top edge (from } \\
\text { shaft axis to inner edge) }\end{array}$ \\
\hline $\mathrm{OR}_{1}$ : & $\begin{array}{l}\text { Outer radius of the runner at the top edge (from } \\
\text { shaft axis to outer edge) }\end{array}$ \\
\hline $\mathrm{OR}_{2}:$ & $\begin{array}{l}\text { Outer radius of the runner at the bottom edge } \\
\text { (from shaft axis to outer edge) }\end{array}$ \\
\hline p: & Pressure $\left(\mathrm{N} / \mathrm{m}^{2}\right)$ \\
\hline$W:$ & Mass $(\mathrm{kg})$ \\
\hline$F:$ & Force $(\mathrm{N})$ \\
\hline $\begin{array}{l}\mathrm{R} 1, \ldots \\
\mathrm{R} 22:\end{array}$ & Runner $1, \ldots$, runner 22 \\
\hline & Computational data \\
\hline & Experimental data. \\
\hline
\end{tabular}

\section{Data Availability}

The runner data used to support the findings of this study are included within the article.

\section{Disclosure}

The funding institute had no role in the design of the study; in the collection, analyses, or interpretation of data; in the writing of the manuscript, or in the decision to publish the results.

\section{Conflicts of Interest}

The authors declare no conflicts of interest.

\section{Authors' Contributions}

TRB and SRS supervised the research. AS, ABT, and AG carried out the study design, data analysis, and interpretation. AS and AG drafted the manuscript. AS, AG, SN, and JD conducted the experiments and data collection. AS, AG, and SN carried out the 3D modeling and simulations. AS and JD participated in fund acquisition. All the authors read and approved the manuscript.

\section{Acknowledgments}

The authors are thankful to the Centre for Energy Studies, Institute of Engineering, Tribhuvan University, and Robotics Club, Pulchowk Campus, Institute of Engineering, Tribhuvan University, for providing workspace and necessary equipment and instruments for experimentation and University Grants Commission, Sanothimi, Bhaktapur, for funds. The authors would also like to thank Dr. Sean
Mulligan, National University of Ireland, Galway, and Mr. Sujan Dulal for their assistance. This research was funded by the University Grants Commission, Sanothimi, Bhaktapur, Nepal, under Small Research Development and Innovation Grant (SRDIG-72/73-Engg-01).

\section{References}

[1] O. D. Thapar, Modern Hydroelectric Engineering Practice in India: Electro-Mechanical Works, Alternate Hydro Energy Centre, Roorkee, India, 2002.

[2] D. Zhou and Z. Deng, "Ultra-low-head hydroelectric technology: a review," Renewable and Sustainable Energy Reviews, vol. 78, pp. 23-30, 2017.

[3] P. Wiemann, G. Müller, and J. Senior, "Review of current developments in low head, small hydropower," in Proceedings of the 32nd IAHR Conference, Venice, Italy, July 2007.

[4] D. Kumar and S. S. Katoch, "Small hydropower development in western Himalayas: strategy for faster implementation," Renewable Energy, vol. 77, pp. 571-578, 2015.

[5] S. J. Williamson, B. H. Stark, and J. D. Booker, "Low head pico hydro turbine selection using a multi-criteria analysis," Renewable Energy, vol. 61, pp. 43-50, 2014.

[6] A. B. Timilsina, S. Mulligan, and T. R. Bajracharya, "Water vortex hydropower technology: a state-of-the-art review of developmental trends," Clean Technologies and Environmental Policy, vol. 20, no. 8, pp. 1737-1760, 2018.

[7] A. Bartholomew, Hidden Nature: The Startling Insights of Viktor Schauberger, Adventures Unlimited Press, Kempton, IL, USA, 2005.

[8] K. D. Brown, "Power generating method and apparatus," Academic Press, Cambridge, MA, USA, US Patent 3,372,905, 1968.

[9] P. S. Kouris, "Hydraulic turbine assembly," US Patent 6,114,773, 2000.

[10] F. Zotlöterer, "Hydroelectric power plant," WO2004061295A2, 2004

[11] S. Mulligan and J. Casserly, "The hydraulic design and optimisation of a free water vortex for the purpose of power extraction," Undergraduate thesis, Institute of Technology Sligo, Sligo, Ireland, 2010.

[12] F. Zotloeterer, "Zotloeterer smart energy systems," 2016, http://www.zotloeterer.com/welcome/gravitation-watervortex-power-plants/economy/.

[13] T. Bajracharya and R. Chaulagain, "Developing innovative low head water turbine," Master's thesis, Center for Applied Research and Development (CARD), Tribhuvan University, Kathmandu, Nepal, 2012.

[14] S. Wanchat and R. Suntivarakorn, "Preliminary design of a vortex pool for electrical generation," Advanced Science Letters, vol. 13, no. 1, pp. 173-177, 2012.

[15] S. Wanchat, R. Suntivarakorn, S. Wanchat, K. Tonmit, and P. Kayanyiem, "A parametric study of a gravitation vortex power plant," Advanced Materials Research, vol. 805-806, pp. 811-817, 2013.

[16] S. Mulligan, J. Casserly, and R. Sherlock, "Hydrodynamic investigation of free-surface turbulent vortex flows with strong circulation in a vortex chamber," in Proceedings of the 5th IAHR International Junior Researcher and Engineer Workshop on Hydraulic Structures, Spa, Belgium, June 2014.

[17] S. Dhakal, S. Nakarmi, P. Pun, A. B. Thapa, and T. R. Bajracharya, "Development and testing of runner and conical basin for gravitational water vortex power plant," 
Journal of the Institute of Engineering, vol. 10, no. 1, pp. 140-148, 2014.

[18] S. Dhakal, A. B. Timilsina, R. Dhakal, D. Fuyal, T. R. Bajracharya, and H. P. Pandit, "Effect of dominant parameters for conical basin: gravitational water vortex power plant," in Proceedings of the IOE Graduate Conference, p. 381, Kathmandu, Nepal, October 2014.

[19] S. Dhakal, A. B. Timilsina, R. Dhakal et al., "Comparison of cylindrical and conical basins with optimum position of runner: gravitational water vortex power plant," Renewable and Sustainable Energy Reviews, vol. 48, pp. 662-669, 2015.

[20] S. Mulligan, J. Casserly, and R. Sherlock, "Experimental and numerical modelling of free-surface turbulent flows in full aircore water vortices," in Proceedings of the SimHydro 2014 International Conference: Modelling of Rapid Transitory Flows, pp. 549-569, Springer, Nice, France, June 2016, Advances in Hydroinformatics.

[21] C. Power, A. McNabola, and P. Coughlan, "A parametric experimental investigation of the operating conditions of gravitational vortex hydropower (GVHP)," Journal of Clean Energy Technologies, vol. 4, no. 2, pp. 112-119, 2016.

[22] M. G. Marian, T. Sajin, and A. Azzouz, "Study of micro hydropower plant operating in gravitational vortex flow mode," Applied Mechanics and Materials, vol. 371, pp. 601605, 2013, Innovative Manufacturing Engineering, Trans Tech Publications Ltd.

[23] P. Wichian and R. Suntivarakorn, "The effects of turbine baffle plates on the efficiency of water free vortex turbines," Energy Procedia, vol. 100, pp. 198-202, 2016, Proceedings of the 3rd International Conference on Power and Energy Systems Engineering, CPESE 2016, Kitakyushu, Japan, September 2016.

[24] S. L. Dixon and C. Hall, Fluid Mechanics and Thermodynamics of Turbomachinery, Butterworth-Heinemann, Oxford, UK, 2013.

[25] B. R. Munson, T. H. Okiishi, W. W. Huebsch, and A. P. Rothmayer, Fluid Mechanics, Wiley, Singapore, 2013.

[26] P. Sritram, W. Treedet, and R. Suntivarakorn, "Effect of turbine materials on power generation efficiency from free water vortex hydro power plant," IOP Conference Series: Materials Science and Engineering, vol. 103, Article ID 012018, 2015.

[27] J. Anderson, Computational Fluid Dynamics; Computational Fluid Dynamics: The Basics with Applications, McGraw-Hill Education, New York, NY, USA, 1995.

[28] H. Versteeg and W. Malalasekera, An Introduction to Computational Fluid Dynamics: The Finite Volume Method, Pearson Education Limited, London, UK, 2007.

[29] C. J. Freitas, "The issue of numerical uncertainty," Applied Mathematical Modelling, vol. 26, no. 2, pp. 237-248, 2002.

[30] F. R. Menter, "Two-equation eddy-viscosity turbulence models for engineering applications," AIAA Journal, vol. 32, no. 8, pp. 1598-1605, 1994.

[31] P. Gullberg and R. Sengupta, "Axial fan performance predictions in CFD, comparison of MRF and sliding mesh with experiments," in Proceedings of the SAE 2011 World Congress \& ExhibitionSAE Technical Paper, Detroit, MI, USA, April 2011.

[32] N. Tonello, Y. Eude, B. de Laage de Meux, and M. Ferrand, "Frozen rotor and sliding mesh models applied to the 3D simulation of the Francis-99 Tokke turbine with Code_Saturne," Journal of Physics: Conference Series, vol. 782, Article ID 012009, 2017.

[33] P. J. Pritchard and J. W. Mitchell, Fox and McDonald's Introduction to Fluid Mechanics, Binder Ready Version, John Wiley \& Sons, Hoboken, NJ, USA, 2016. 